\title{
GRAN GRUTA GRABADA DE CHIQUIMII. NOTICIA ACERCA DE SU HALLAZGO Y REDESCUBRIMIENTO CIEN AÑOS DESPUÉS
}

\section{THE GREAT ENGRAVED GROTTO AT CHIQUIMII. ITS DISCOVERY AND REDISCOVERY ONE HUNDRED YEARS LATER}

\section{Alina Álvarez larrain * , Fernando CABrera * * JUAN PABlO CARBONelli $* * *$}

En este trabajo se describen y reinterpretan los motivos rupestres de la Gruta Grabada de Chiquimí (valle de Yocavil, provincia de Catamarca, Argentina). Dichos motivos fueron originalmente encontrados por Adán Quiroga en la década de 1920 y redescubiertos luego de cien años de permanecer ocultos en un rincón del valle. En primer lugar, se efectúa una reseña del trabajo pionero del autor. A continuación se sitúa la gruta en el paisaje, dando a conocer los principales sitios arqueológicos cercanos. Finalmente, se realiza un análisis morfológico de las manifestaciones rupestres y un estudio del contexto de producción y funcionalidad de las mismas. Utilizando como guía los motivos presentes en el arte rupestre del Noroeste Argentino y norte chileno y sus interpretaciones asociadas se ubica temporalmente la elaboración de los grabados en el momento de las sociedades agropastoriles.

Palabras clave: arte rupestre, gruta de Chiquimí, paisaje, Noroeste Argentino, valle de Yocavil, primer milenio DC, Período Tardío

In this paper the rock art motifs found in the Great Engraved Grotto at Chiquimi (Yocavil Valley, Catamarca Province, Argentina) are described and reinterpreted. The motifs were originally found by Adan Quiroga in the 1920s and rediscovered after being forgotten for 100 years in a remote corner of the valley. A review of Quiroga's pioneering work is presented, followed by a description of the Grotto's location in the landscape, with mention of nearby major archaeological sites. Lastly, a morphological analysis of the rock art works is undertaken, along with a study of their production context and functionality. Using the ancient rock art motifs found in Northwest Argentina and northern Chile and their associated interpretations, the engravings are located chronologically during the time of agropastoral societies.

Key words: rock art, Chiquimi Grotto, landscape, Northwest Argentina, Yocavil Valley, first millennium AD, Late Period

\section{INTRODUCCIÓN}

Existen pocos trabajos que mencionan el arte rupestre del valle de Santa María o Yocavil (Liberani \& Hernández 1877; Ambrosetti 1897; Boman 1908; Bruch 1911; Quiroga 1931; Lorandi 1966; Fiore 1997; Álvarez et al. 1998 Ms). El panorama se amplía ligeramente cuando consideramos el arte de zonas aledañas como el valle del Cajón (Vargas \& Palamarczuk 1999 Ms; De Hoyos \& Lanza 2000; Nastri et al. 2009) y el valle Calchaquí (Lanza 2000; Ledesma \& De Hoyos 2001; Williams 2003; Ledesma 2005; Lo Celso \& Ledesma 2005; Ledesma 2006/2007; Ledesma \& Subelza 2009). Algunos tuvieron como objetivo dar cuenta de la presencia de petroglifos o aleros con arte, mientras que otros se centraron en las técnicas de ejecución o la distribución de los mismos en el espacio y su asignación temporal. Así, el arte rupestre de Yocavil sigue siendo un registro arqueológico poco conocido, careciendo de secuencias estilísticas calibradas, asociaciones contextuales o trabajos integradores de algún tipo.

En este trabajo realizamos un aporte para seguir avanzando en el conocimiento de las manifestaciones rupestres en Yocavil a partir de la relocalización de un alero con grabados que ha permanecido casi cien años

* Alina Álvarez Larrain, Museo Etnográfico J. B. Ambrosetti, Universidad de Buenos Aires, Moreno 350, Buenos Aires (1091), Argentina, email: alinaalvarezlarrain@gmail.com

* Fernando Cabrera, Museo Etnográfico J. B. Ambrosetti, Universidad de Buenos Aires, Moreno 350, Buenos Aires (1091), Argentina, email: fergc_18@yahoo.com

*** Juan Pablo Carbonelli, Museo Etnográfico J. B. Ambrosetti, Universidad de Buenos Aires, Moreno 350, Buenos Aires (1091), Argentina, email: juanp.carbonelli@gmail.com 
sin investigaciones desde su estudio original por Adán Quiroga (1931). ${ }^{1}$ Se buscará entonces analizar los grabados de la gran Gruta Grabada de Chiquimí (GCh) a partir de distintas variables, como su ubicación en el paisaje y en contexto con los sitios arqueológicos existentes en la zona, los motivos y los temas presentes en los grabados y los contextos de producción y funcionalidad. Para lograr estos objetivos nos basaremos en las interpretaciones de los motivos y las secuencias desarrolladas para otros sectores del Noroeste Argentino (NOA) y de las regiones chilenas de San Pedro de Atacama y del río Loa, así como en las representaciones iconográficas presentes en distintos soportes, principalmente la cerámica, para la identificación de rasgos iconográficos comunes a estilos ya conocidos. ${ }^{2}$

\section{VIAJE DE QUIROGA POR CALCHAQUÍ Y HALLAZGO DE LA GRUTA}

A finales de la década de 1920, Quiroga emprende un viaje por los valles calchaquíes con el objetivo de realizar un registro exhaustivo del folclore local y del arte rupestre. La obra Petrografías y pictografías de Calchaquí (1931) es aún hoy una de las más importantes sobre arte rupestre del Noroeste Argentino, por la cantidad de manifestaciones rupestres reproducidas.

Es en el marco de este viaje que Quiroga, junto a Holmberg, dibujante naturalista, diera con la que llamara gran Gruta Grabada de Chiquimí. ${ }^{3}$ Según narraba Quiroga, la GCh se encontraba "casi frente a San José, valle de Santa María, en el lugar denominado Entre Ríos, y en lo más escarpado del cerro [...] en la margen derecha y al borde del mismo arroyo de Entre Ríos" (Quiroga 1931: 34-35). Al parecer, estas referencias no resultaron suficientes para su localización, dada la búsqueda infructuosa de la GCh en dos oportunidades, posteriormente a su hallazgo original (Lorandi 1966; Renard 1988: 47). ${ }^{4}$

Quiroga describe la GCh como una formación natural cavada por las aguas en la arenisca, situada en un lugar poco transitado, lo cual la habría protegido de la acción destructora de los saqueadores. Su soporte de areniscas blandas ha permitido así el fácil grabado (Quiroga 1931: 35). Los dibujos comenzaron a ser relevados desde la izquierda hacia la derecha de la gruta, quedando conformadas cinco secciones principales, que, según criterios de Quiroga, corresponderían al orden original de elaboración.

Quiroga (1931: 4) ve representada en la GCh una leyenda prehistórica de héroes mitológicos, solares o cósmicos. Básicamente, atribuye las imágenes a la leyenda de Huayrapuca, o Madre del Viento, que recupera del folclore local de los valles. Según el autor (1900: 403), Huayrapuca significa Viento Colorado o "remolino de viento en día de tempestad", tomando su coloración del polvo que levanta cuando corre por los terrenos áridos del valle. Una característica importante de Huayrapuca, y que va a tener su correlato directo en la interpretación que el autor haga sobre los grabados, es la multiplicidad de formas en que se lo representa. Es debido a esto que en las representaciones simbólicas puede aparecer con una cabeza monstruosa, como de dragón o con cabeza de serpiente, o guanaco, o bien con cabeza y cuello de guanaco, cuerpo de suri y cola de serpiente, o con cara humana y cuerpo conformado por distintos animales (Quiroga 1900). ${ }^{5}$

Huayrapuca es básicamente un mito femenino, la Madre del Viento o La Viento; sin embargo, procrea tanto con Pachamama como con El Nublado, este último su pariente y principal enemigo. Huayrapuca lucha constantemente contra El Nublado, dispersándolo cuando sopla en medio de la tempestad, mientras este recibe en su seno los dardos candentes del terrible Inti-Illapa, la serpiente relámpago. Cuando La Viento sopla fuerte puede arrasar todo a su paso, pero también a ella se debe la fecundación de la tierra, dado que del combate entre ambos la Madre Tierra resulta fecundada, por lo cual el indio propicia a Huayrapuca para aplacar su ira y a la vez pedir que fecunde la naturaleza con su lluvia (Quiroga 1900: 407-408). ${ }^{6}$ Para Quiroga, toda la GCh se presenta como un cuadro pictórico que relata una tragedia celeste en sus diversas escenas. Reproduciremos aquí la interpretación que nos brinda el autor por sectores.

La primera parte de la GCh representa el trazado de un pueblo, en la parte inferior derecha de la lámina (fig. 1a). Las líneas y los cuadros son interpretados como un plano de construcciones, en el cual se pueden observar las casas y las fortalezas. Sobre el pueblo caen flechas o proyectiles, algunos ya en el suelo entre las casas. Los símbolos geométricos espiralados que se observan por encima (fig. 1b) son interpretados por Quiroga (1931: 41) como la representación simbólica esquemática de Huayrapuca o la Madre del Viento:

[...] a la cual el indio conjura para que no barra las tolderías o eche al suelo el maíz de las eras, cuando abandonando su guarida de las cumbres, viene como un torbellino de Viento colorado, armada de relámpagos, para destruir cuanto a su paso se encuentre. Sería contra esta Huayrapuca, simbólicamente representada, contra quien se arrojan las flechas y proyectiles luminosos.

En la segunda parte, nuevamente se ve representado el pueblo y sobre él "la lucha encarnizada de genios, héroes y guerreros" (Quiroga 1931: 41) (fig. 2a). Combatientes detrás de sus escudos luchan contra Huayrapuca en 

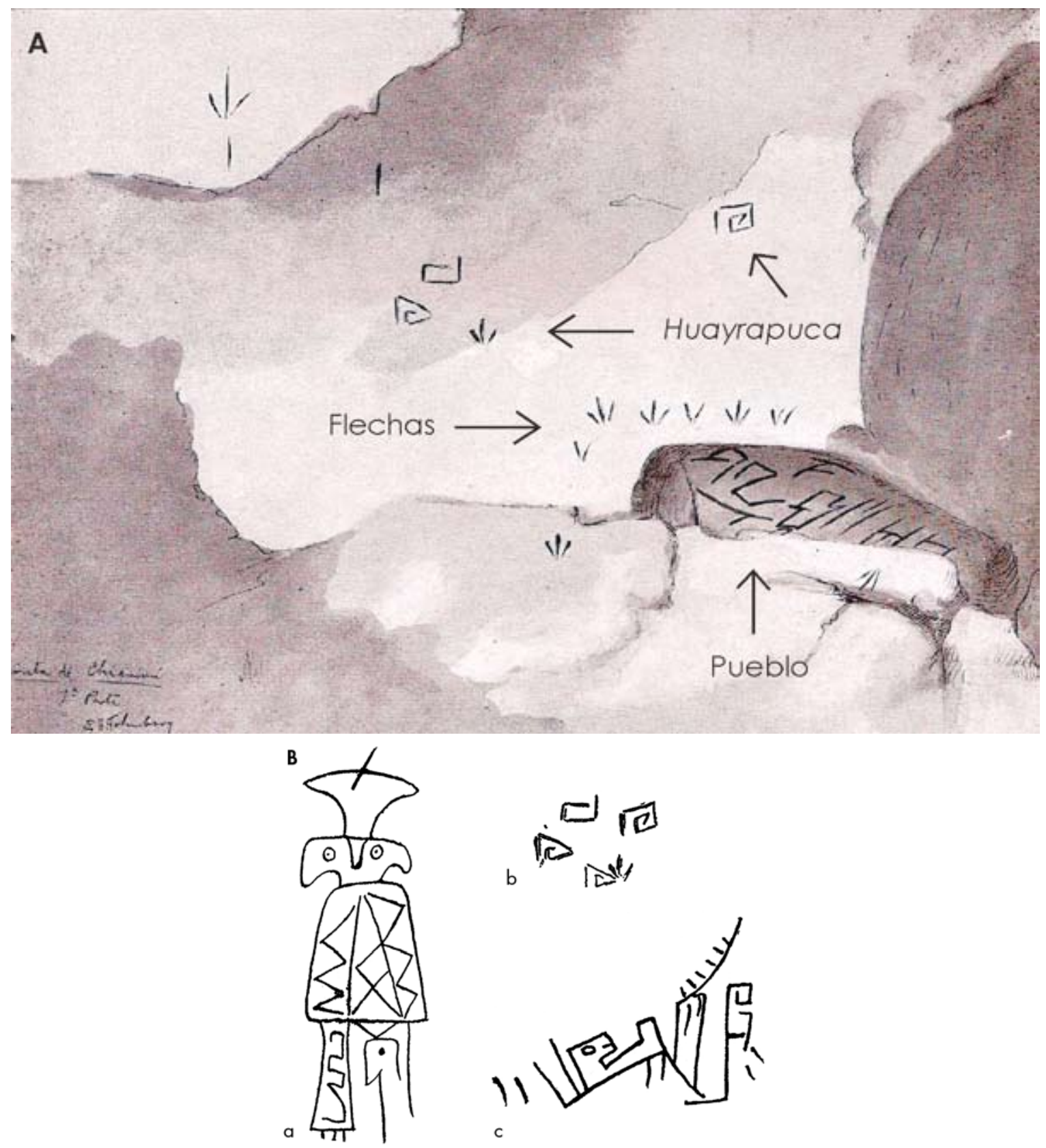

Figura 1. a) Gruta de Chiquimí, primera parte (tomado de Quiroga 1931: 39, fig. 36); b) Motivos que representan a Huayrapuca (tomado de Quiroga 1931, fig. 27, fig. 29, fig. 38).

Figure 1. a) Chiquimi Grotto, part one (after Quiroga 1931: 39, fig. 36); b) Motifs representing Huayrapuca (after Quiroga 1931, fig. 27, fig. 29, fig. 38).

una escena dinámica. Los incontables trazos lineales entre los guerreros responden a flechas, rayos y lluvia de fuego, dado que toma parte de la batalla Inti-Illapa, El Relámpago, la serpiente rayo, ser de la cosmogonía andina. Aquí, Quiroga cambia ligeramente la explicación y plantea que El Relámpago y El Nublado son ambos enemigos de Huayrapuca, la cual está representada en la parte inferior de esta sección en un nuevo motivo, una serie de figuras geométricas donde el autor cree ver un ser con cabeza de guanaco (fig. 1b-c). ${ }^{7}$

En la tercera parte la batalla parece continuar y los proyectiles siguen cayendo (fig. 2b). Acosada por las 
flechas, Huayrapuca se refugia en el costado izquierdo del panel. Ha tomado forma humana, apareciendo como un personaje de grandes dimensiones que porta un tocado, según Quiroga, un casco fálico luminoso (fig. 1b-a). En el cuerpo porta una especie de túnica o unku con motivos geométricos de triángulos, símbolo también fálico (Quiroga 1899). En la parte inferior parece tener las piernas, estando la izquierda representada por una greca y la derecha por la cabeza de un suri (Quiroga 1931: 43).

En la cuarta parte (fig. 3a) Quiroga ve representada a Huayrapuca nuevamente como un espiral de trazos rectos. La batalla parece estar llegando a su fin y un héroe o guerrero se hace presente en el centro de la escena, es El Nublado que, levantando las manos hacia el cielo, desvía los rayos y pide que se calmen las iras celestes. De la batalla entre la Madre del Viento y El Nublado suelen producirse los fenómenos meteorológicos que acarrean las lluvias y los granizos en los valles. De esta manera, el resultado final de la tragedia que nos narra Quiroga (1931: 453) es la fecundación de la tierra y las especies, gracias a que el deseo de agua abundante ha sido satisfecho.

Es por eso que al concluir los combates, todo el resto del simbolismo de la lámina se refiere a agua, lluvia, fecundidad, apareciendo entonces esa figura humana, que tiene los brazos alzados como en señal de súplica [...] Puede muy bien -por tratarse de un ser femenino, con mamas, vientre abultado en estado de preñez y con su gran vulva-mortero-, que se trate de la Pacha Mama, la divinidad fecunda que sabemos es la Madre de la Tierra, el numen propicio de la producción, con forma de mujer.

El resto de los motivos geométricos reproducidos en la lámina son interpretados como símbolos meteorológicos que anuncian la llegada de la lluvia. Refuerzan esta interpretación las figuras de la quinta sección de la GCh (fig. 3b). La lucha ha cesado. El guerrero presente en la parte superior izquierda ya no lleva armas ni arroja proyectiles, parece ser "testigo de la obra que los genios del bien han realizado, obra final que está patente en la lámina, en la que se expresa que llueve sobre la tierra a torrentes" (Quiroga 1931: 45). La figura que aparece denotada con la letra (a) representa para Quiroga nuevamente una casa, o el pueblo, por el cual se inició la tragedia. El círculo (e) parece tratarse de la Madre Tierra, con sus cerros, mientras que (f) sería el río Pilcomayo. ${ }^{8}$ Se suman a esta escena la gran cruz con contorno (c), símbolo de la lluvia y por tanto de la fecundidad, el triángulo (b), símbolo fálico de la reproducción y los relámpagos (d), símbolos de la tormenta (Quiroga 1899).

Quiroga (1931) llega a la conclusión de que los petroglifos y las pictografías calchaquíes no son letras ni caracteres fonéticos, es decir, que no hay escritura o lenguaje en ellos, sino dibujos y signos convencionales. Según el autor, en los petroglifos está expresado el pensamiento secular del indio ya sea ideológica o simbólicamente. Así, las piedras grabadas o pintadas son rocas sagradas que se presentan como altares al aire libre donde se hace el voto o pedido a las divinidades. Su producción responde a formas convencionales colectivas para representar objetos o cosas. Esto facilitaría, a la vez, su interpretación, para aquellos que estuvieran al tanto de cómo se desarrollaba la vida en estos valles, dado que los símbolos tendrían relaciones directas con la cosa representada.

Las interpretaciones de Quiroga son interesantes y recuperan un folclore hoy poco mencionado en los valles. Sin embargo, algunos supuestos son cuestionables. Al considerar a las distintas secciones de la GCh como una sucesión de escenas que nos cuentan una tragedia mitológica, Quiroga da por sentado que todos los motivos son sincrónicos y que siguen una secuencia. Habría que analizar qué sucede con los motivos que aparecen superpuestos y la posibilidad de un uso prolongado de la GCh a la largo del tiempo. Por otro lado, la interpretación de los motivos a base del mito de Huayrapuca, si bien no puede ser descartada, por momentos parece excesivamente forzada. Ejemplo de esto es la cantidad de motivos diversos que estarían representando a esta divinidad (fig. 1b). Por último, es importante resaltar que si bien los dibujos de Holmberg son un documento relevante, dado que determinan un ante quem para los grabados, los nuevos relevamientos llevados a cabo muestran diferencias cualitativas considerables en algunas imágenes.

\section{VALLE DE YOCAVIL. ARQUEOLOGÍA Y PAISAJE}

La GCh se ubica en la porción catamarqueña del valle semiárido de Yocavil (departamento de Santa María), continuación hacia el sur de los valles calchaquíes en la región valliserrana del NOA. El valle de Yocavil conforma una zona natural de tránsito, tanto en sentido norte-sur (comunicándose con el alto valle Calchaquí al norte y el valle de Hualfín al sur como en sentido este-oeste (conectándose con la puna al oeste y la zona de las yungas tucumanas al este) a través de las quebradas transversales. Limitado hacia el oeste por las sierras del Cajón o Quilmes y hacia al este por las sierras del Aconquija, cuenta con una asimetría geomorfológica marcada, presentando conos de deyección en el oeste y niveles aterrazados en el este que generan un paisaje 

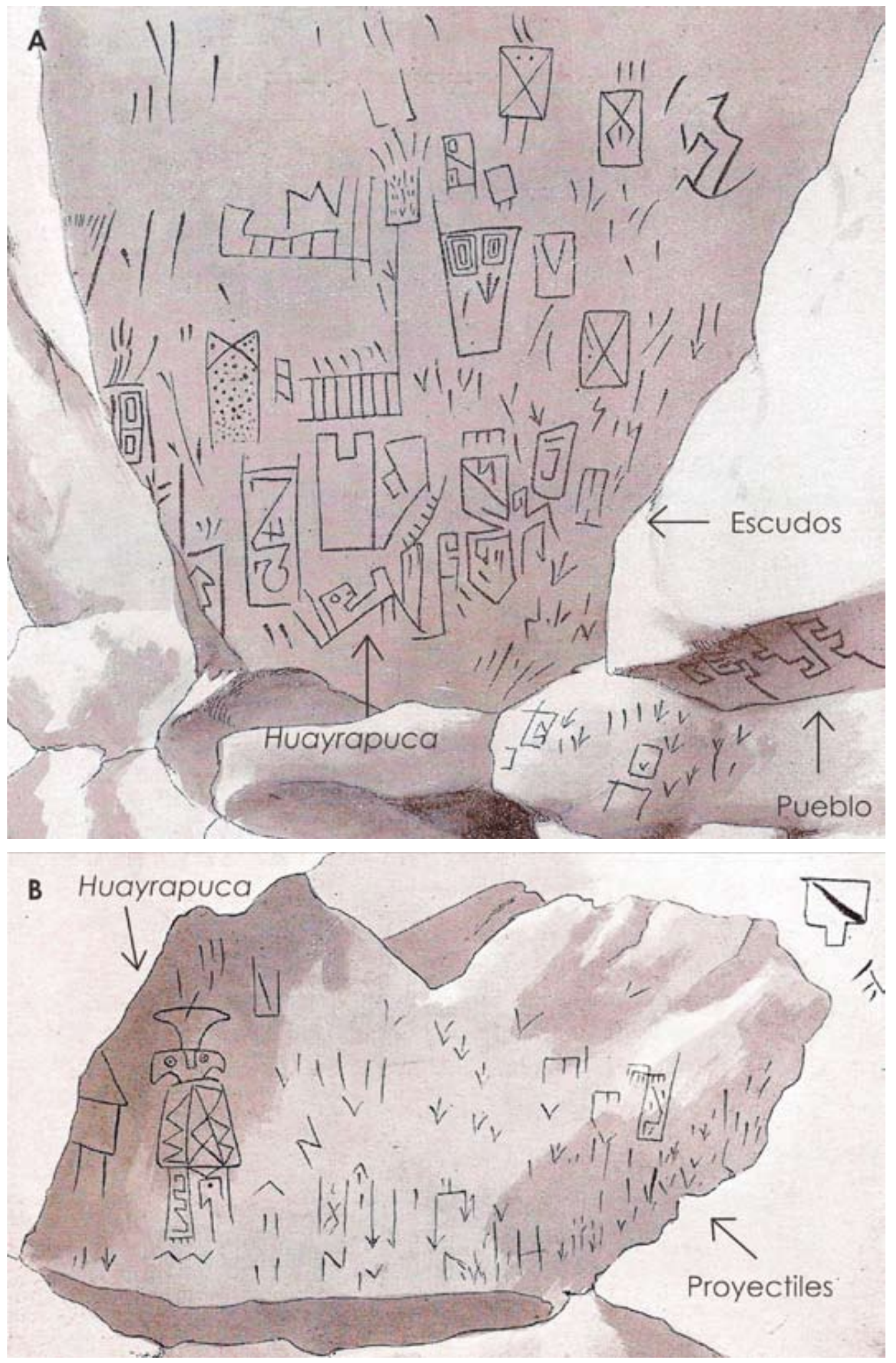

Figura 2. a) Gruta de Chiquimí, segunda parte (tomado de Quiroga 1931: 40, fig. 37); b) Gruta de Chiquimí, tercera parte (tomado de Quiroga 1931: 42, fig. 40).

Figure 2. a) Chiquimi Grotto, part two (after Quiroga 1931: 40, fig. 37); b) Chiquimi Grotto, part three (after Quiroga 1931: 42, fig. 40). 

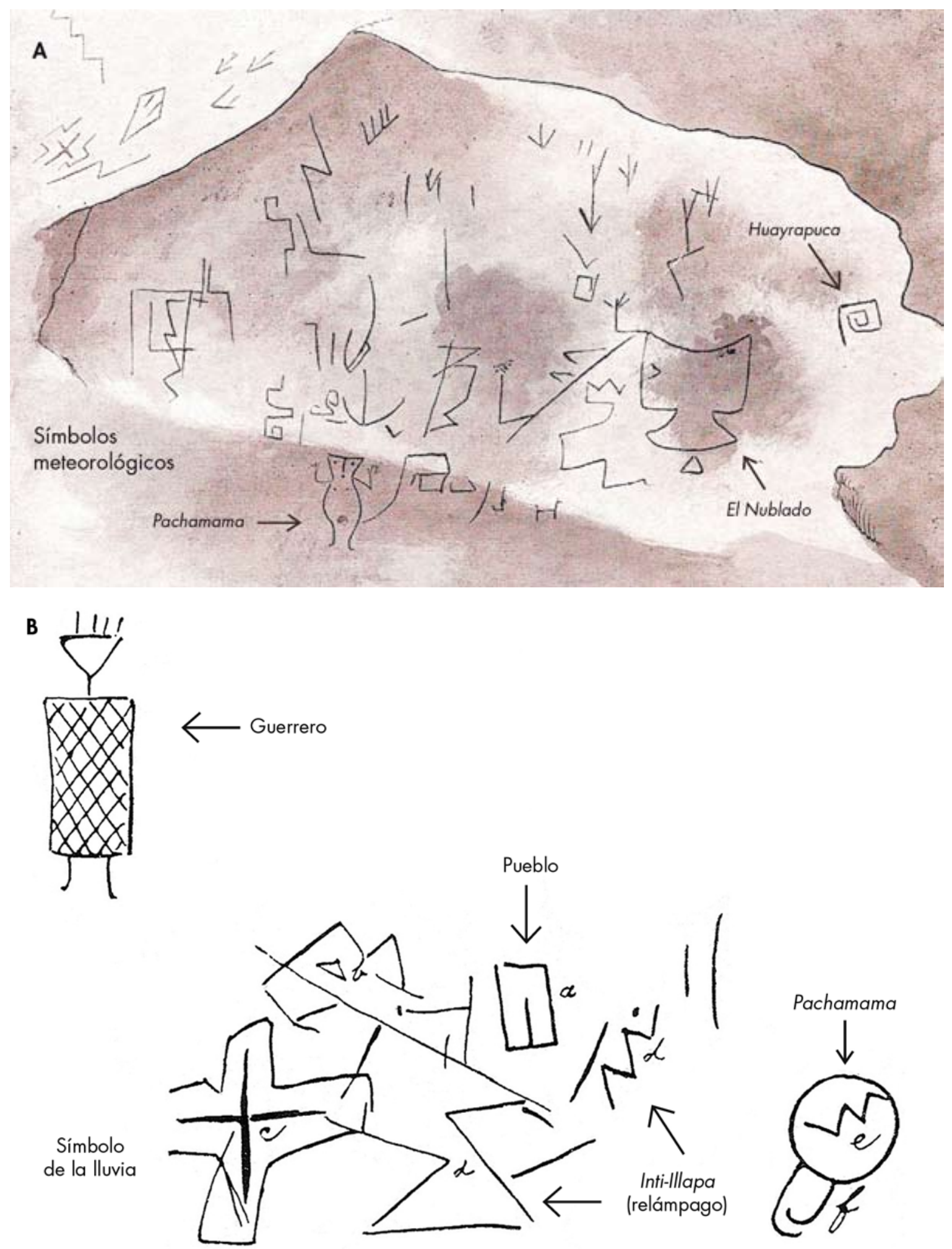

Figura 3. a) Gruta de Chiquimí, cuarta parte (tomado de Quiroga 1931: 43, fig. 42); b) Gruta de Chiquimí, quinta parte (tomado de Quiroga 1931: 45, fig. 44).

Figure 3. a) Chiquimi Grotto, part four (after Quiroga 1931: 43, fig. 42); b) Chiquimí Grotto, part five (after Quiroga 1931: 45, fig. 44). 
quebrado (Frenguelli 1936; Ruiz Huidobro 1972) (fig. 4), característica del paisaje que pudo tener incidencia en la baja visibilidad y, por ende, en la relocalización tardía de la GCh.

El sistema de drenaje de Yocavil es un factor importante al estudiar sus asentamientos prehispánicos, incluida la GCh. El río Santa María, principal curso hídrico, corre por un amplio lecho fluvial de $35-45 \mathrm{~km}$, transportando agua todo el año, pero siendo su caudal escaso durante el estiaje (Ruiz Huidobro 1972). En la porción meridional del valle, la margen oriental presenta una serie de formaciones sedimentarias terciarias y cuaternarias surcadas por ríos y arroyos de agua permanente como los cursos de Amaicha, Yasyamayo, San José, Entre Ríos, Yapes, Andalhuala, El Molle, Ampajango y Pajanguillo que descienden del macizo del Aconquija y desembocan en el río Santa María, permitiendo el asentamiento humano con actividades agrícolas bajo riego.

Consideramos que los sitios deben ser analizados en una doble relación, entre ellos y con su espacio (Ledesma 2006-2007), tanto el natural como el espacio arqueológico circundante. Por lo tanto, daremos cuenta aquí de los sitios de mayor relevancia del área. Arqueológicamente, el valle de Yocavil es ampliamente conocido por las ruinas de poblados pertenecientes al Período Tardío como Quilmes, Fuerte Quemado, Rincón Chico y Loma Rica, de alta visibilidad y arquitectura compleja (Ambrosetti 1897; Bruch 1911; González, A. 1954; Pelissero \& Difrieri 1981; Tarragó 1987, 1995, 2000; Raffino 1991; Nastri 1997-98, 2001). Sin embargo, en las últimas décadas se ha reavivado el interés por el primer milenio DC en el valle (Tarragó \& Scattolin 1999; Scattolin 2000, 2003, 2007; Baigorria \& Spano 2007; Belotti 2007; Bugliani 2008; Álvarez Larrain et al. 2009; Carbonelli 2009; Scattolin et al. 2009). Al referirnos al paisaje donde se inserta la GCh debemos mencionar algunos sitios de importancia, tanto del Período Tardío (Desarrollos Regionales) como del primer milenio DC (sensu Scattolin 2000), que demuestran que la zona fue ocupada durante todo el período agroalfarero, siendo factible que algunas de estas poblaciones sean las productoras de los grabados.

Dentro del último período se ubica temporalmente Soria 2, sobre una meseta al norte de la localidad de Andalhuala La Banda. La meseta de Andalhuala, de 250 ha, presenta en superficie estructuras que parecen responder a un uso agrícola tardío (Álvarez Larrain 2010). El sitio Soria 2 se halló por debajo de dichas estructuras y se encuentra conformado por un conjunto arquitectónico de al menos dos recintos, dentro de los cuales se ha definido un espacio de uso doméstico y funerario. El conjunto cerámico fino, integrado por piezas pulidas pardo-grisáceas negruzcas de pasta compacta, apunta al Período Temprano (Spano 2008). El fechado

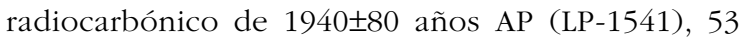
cal AC-342 cal DC (dos sigma - curva de calibración ShCal04, McCormac et al. 2004), obtenido a través de una muestra de carbón proveniente de un fogón del piso de ocupación, confirmó dicha asignación temporal (Álvarez Larrain et al. 2009).

A $3 \mathrm{~km}$ hacia el noroeste de Soria 2 se encuentra la Loma Rica de Shiquimil (LRS). La meseta de cumbre horizontal, elevada $100 \mathrm{~m}$ sobre el nivel de base, conforma un área habitacional de 2,45 ha, desde donde se obtiene un dominio visual de todo el valle y de las poblaciones instaladas en los sectores bajos (González, A. 1954; Tarragó et al. 1988). Los estilos alfareros encontrados -estilos San José/Shiquimil, Loma Rica- parecen indicar una ocupación temprana dentro del Tardío. Remodelaciones posteriores en la plaza oriental fueron asignadas a la llegada del Inka, avaladas por la presencia de artefactos cerámicos de dicha filiación (González \& Tarragó 2005). Dentro de los procesos sociopolíticos que antecedieron a la ocupación inkaica, LRS fue interpretada como un pukara, centro de poder político con un dominio territorial de singular extensión del cual dependían otros poblados secundarios y los sectores de producción agrícola y ganadera circundantes (Tarragó 2000).

Como se mencionó, para los momentos tardíos la meseta de Andalhuala -que para los tiempos de Soria 2 pudo ser el emplazamiento de unidades de vivienda entre campos de cultivos-, parece haber tenido un uso con fines principalmente productivos. Distintas estructuras se presentan como canales, andenes, aterrazados y canchones. Algunas de ellas presentan recintos circunscritos, que tal vez sean las unidades de vivienda de las personas dedicadas a las tareas agrícolas. Algunas de estas estructuras fueron registradas bajo el nombre de Loma Alta, dada su proximidad a la formación natural con dicho nombre ubicada al norte (Copello $1991 \mathrm{Ms}$ ). Esta zona instalada en los terrenos bajos debió ser el núcleo de producción agropecuaria que abastecía a las poblaciones residenciales instaladas en lo alto de la LRS durante los tiempos tardíos (Álvarez Larrain 2009).

\section{REDESCUBRIENDO LA GRUTA GRABADA DE CHIQUIMI}

En marzo de 2008, en el marco de una campaña de prospección de nuevos sitios arqueológicos, fueron fotografiados paredones de arenisca que contaban con grabados. ${ }^{9}$ Las fotos sacadas en esa oportunidad fueron 


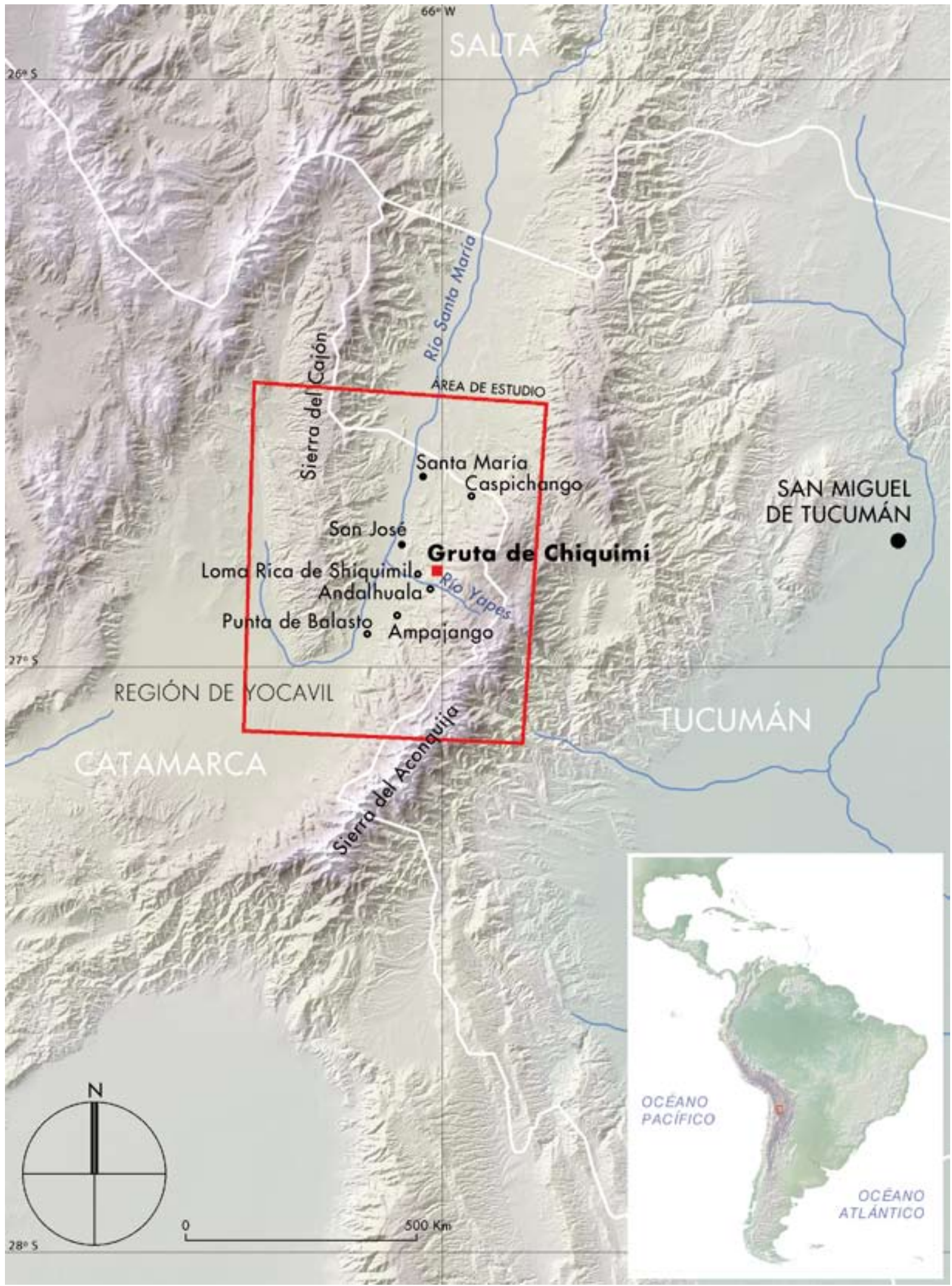

Figura 4. Mapa del valle de Yocavil con las principales localidades arqueológicas y la ubicación de la Gruta Grabada de Chiquimí. Figure 4. Map of the Yocavil Valley, indicating major archaeological sites and the location of the Engraved Grotto at Chiquimi. 
comparadas con los dibujos realizados por Holmberg en la GCh, constatándose que se trataba de las mismas representaciones.

El pueblo de Entre Ríos se encuentra surcado por el río homónimo de caudal permanente. El camino troncal del pueblo sigue de manera paralela el curso de agua por el sector sur del pueblo, para luego cruzar el río y continuar por la margen norte. Tomándose el camino troncal desde la primera casa del pueblo se llega a la intersección con el lecho de un curso de agua estacional. El trayecto continúa siguiendo este curso estacional con rumbo sur, en dirección a Andalhuala La Banda. Tras una hora aproximada de caminata, el cauce queda encajonado entre dos formaciones de arenisca, que van estrechando el sendero formando un cañadón donde se encuentran los grabados (2651'18,9"S - 66 01'49,2"W) (fig. 5). Es importante mencionar que si bien se accedió a la GCh desde la localidad de Entre Ríos, como debió hacer Quiroga originalmente, razón por la cual le diera el nombre de Chiquimí, la misma se encuentra más próxima a la localidad de Andalhuala y en las cercanías de conocidos sitios arqueológicos como la Loma Rica de Shiquimil o Soria 2.

La GCh es una cavidad creada sobre una formación de arenisca por la acción de las aguas estacionales a tres metros sobre el nivel del cauce semipermanente. La longitud del alero es $17,5 \mathrm{~m}$, siendo el ancho máximo de $3,3 \mathrm{~m}$. La altura máxima, coincidente con la línea de goteo, es de 5,25 m, mientras que la altura mínima, donde se encuentra el techo con la parte más baja de la pared, es de 1,85 m. Los grabados se encuentran ubicados dentro de una franja, no pudiendo una persona de pie alcanzar la totalidad de las figuras dibujadas. Parte del piso, el cual está conformado por arenisca consolidada, se encuentra expuesto. El resto del piso del alero, un sector de $2 \mathrm{~m}^{2}$, se encuentra cubierto por sedimento fino, siendo su potencia de 0,5 $\mathrm{m}$ aproximadamente. En términos generales, los grabados presentan un buen estado de conservación, exceptuando sectores alterados por la acción de aguas que escurren por los paredones, detritos de aves y manchas de color obscuro producto de restos adheridos posiblemente de vegetales, de lo cual resulta que algunos motivos se encuentren confusos (fig. 6).

En total se contabilizaron 23 paneles que fueron denominados alfabéticamente de izquierda a derecha (fig. 7). Cada panel fue medido, fotografiado y dibujado en croquis y los motivos fueron definidos a base de los croquis a escala elaborados en el campo. Se registraron también las posibles variaciones en las técnicas de los

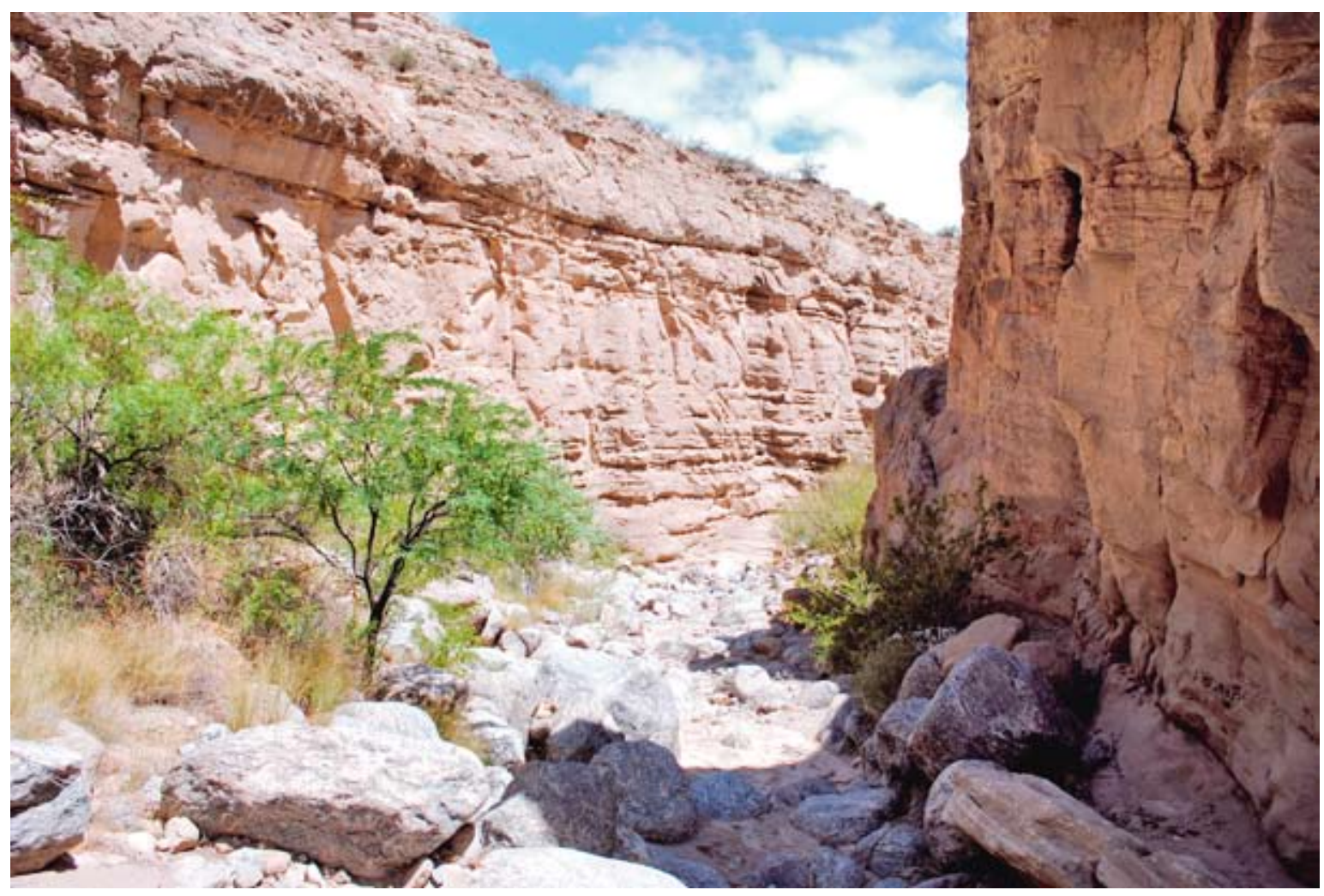

Figura 5. Cañadón donde se encuentra la Gruta de Chiquimí.

Figure 5. Gully where the Chiquimi Grotto is located. 
grabados y las superposiciones, que pudieran responder a distintos momentos de la ejecución. Junto con el registro de los grabados se realizó un primer sondeo exploratorio de 50 por $70 \mathrm{~cm}$ dentro de la línea de goteo, a fin de detectar otras evidencias de ocupación en el sitio. El sondeo alcanzó una profundidad de $45 \mathrm{~cm}$, llegando a nivel de roca madre, sin registro de material cultural.

Las manifestaciones, en su totalidad grabadas, responden en su mayoría a la técnica de incisión (Fiore 2007). Se pudo constatar también la presencia de la técnica de horadado (Drilling, sensu Fiore 2007: 156) en escasos motivos. Si bien dentro de los motivos incisos se observan variaciones de profundidad de los surcos, variando entre los $0,1 \mathrm{~cm}$ y los $1,1 \mathrm{~cm}$, la mayoría de los motivos presenta 0,2 a $0,3 \mathrm{~cm}$. Con respecto al ancho de los surcos, este varía entre los $0,2 \mathrm{~cm}$ y los $2,8 \mathrm{~cm}$, siendo las medidas más frecuentes $0,5 \mathrm{~cm}$ y $0,6 \mathrm{~cm}$.

Cuando uno aprecia la GCh en conjunto, llama la atención la numerosa cantidad de trazos presentes y el grado de aglomeración, condiciones que dificultaron muchas veces la delimitación de los motivos como unidades de ejecución (sensu Gradín 1978). Si bien se han postulado diferentes clasificaciones de las representaciones rupestres (Gradín 1978; Aschero 1988),

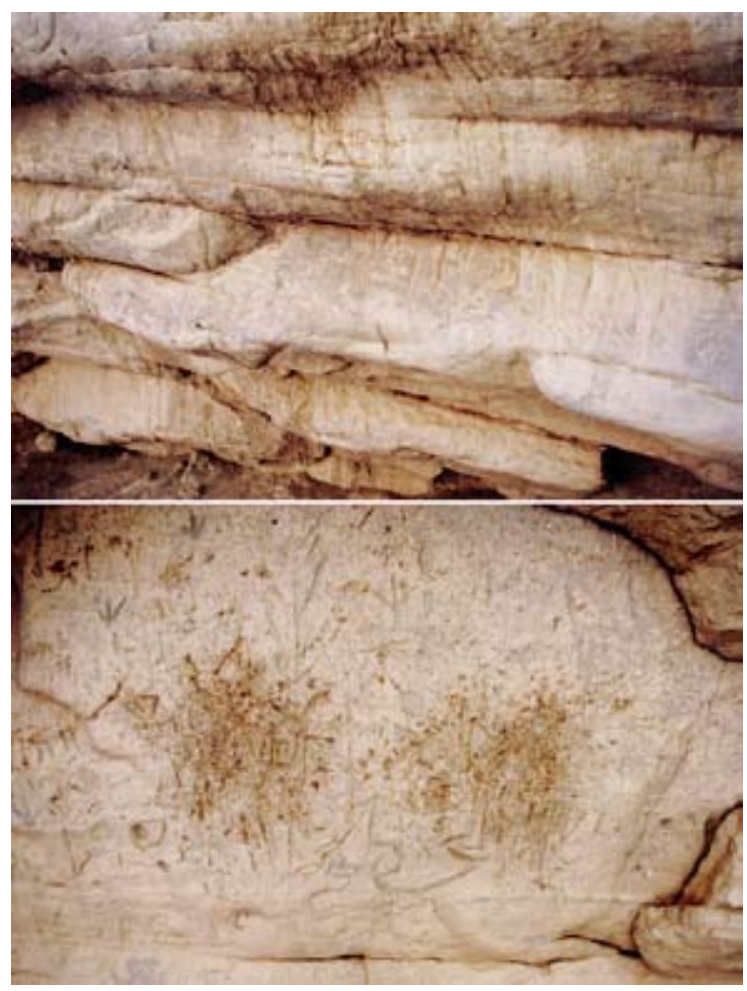

Figura 6. Sectores de la Gruta de Chiquimí alterados por manchas de escurrimiento y acreciones.

Figure 6. Sectors of the Chiquimi Grotto altered by runoff stains and accretions. nosotros clasificaremos a los motivos en tres grupos: motivos figurativos (antropomorfos y zoomorfos), motivos geométricos y motivos indeterminados. En total fueron contabilizados 594 motivos, de los cuales 436 son geométricos, 63 son indeterminados y 95 son figurativos (64 zoomorfos y 31 antropomorfos) (Gráfico 1).

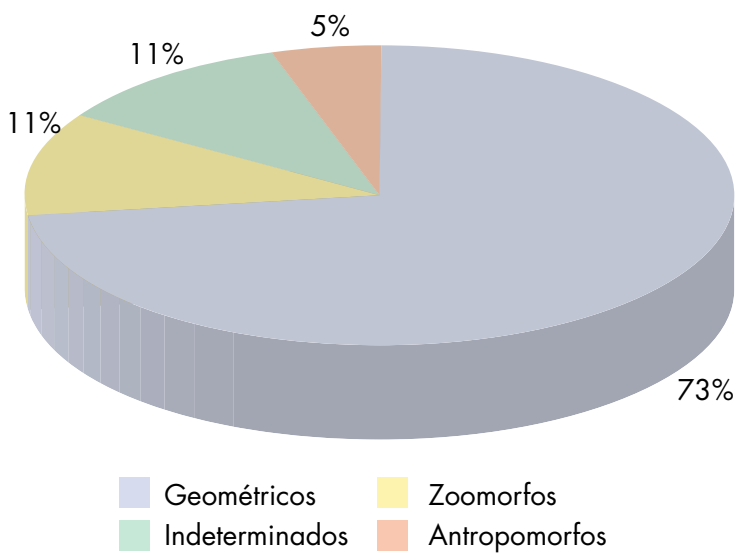

Gráfico 1. Porcentajes de motivos representados en la Gruta de Chiquimí.

Graph 1. Types of motifs found in the Chiquimi Grotto.

Los paneles B, H, N, O y P son los que evidencian mayor cantidad de motivos, presentando elementos de las cuatro categorías. Los motivos geométricos predominan en la totalidad de los paneles, con excepción del panel U que solo contiene un motivo indeterminado. En el panel B se encuentra la mayor concentración de antropomorfos, mientras que en el panel $\mathrm{H}$, la mayor concentración de zoomorfos (Gráfico 2).

De los 23 paneles, ocho cuentan con superposiciones. En general, los paneles presentan entre una y cuatro superposiciones, exceptuando el panel $\mathrm{O}$ que cuenta con 11 superposiciones. Si bien no se pudo observar una clara diferencia en el trazo de los surcos de los motivos superpuestos ni una recurrencia en el tipo de motivos que se superponen, podemos mencionar que las líneas que cortaban -se superponían- eran en general más gruesas que las líneas que eran cortadas, no pudiéndose constatar la situación inversa. Así, las técnicas de ejecución y las superposiciones no son variables contundentes que indiquen a priori una diacronía en los grabados.

\section{Motivos geométricos}

Los motivos geométricos están definidos a partir de la complejidad de asignarles un referente (Gradín 1978). Dentro de esta categoría se puede observar una amplia 


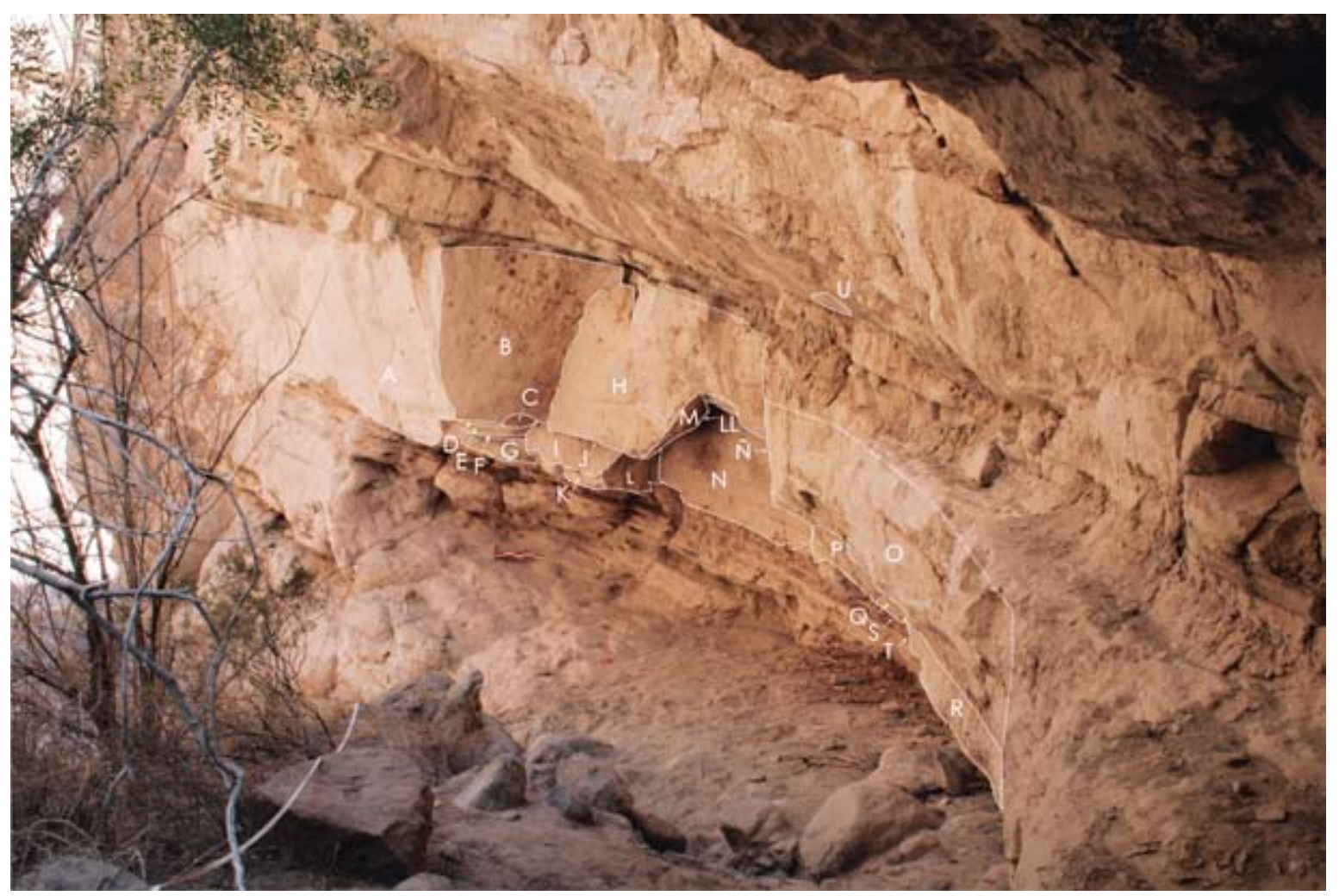

Figura 7. Vista general hacia el norte de la Gruta de Chiquimí con demarcación de paneles. Figure 7. General view of the Chiquimi Grotto, looking northward, with panels indicated.

110

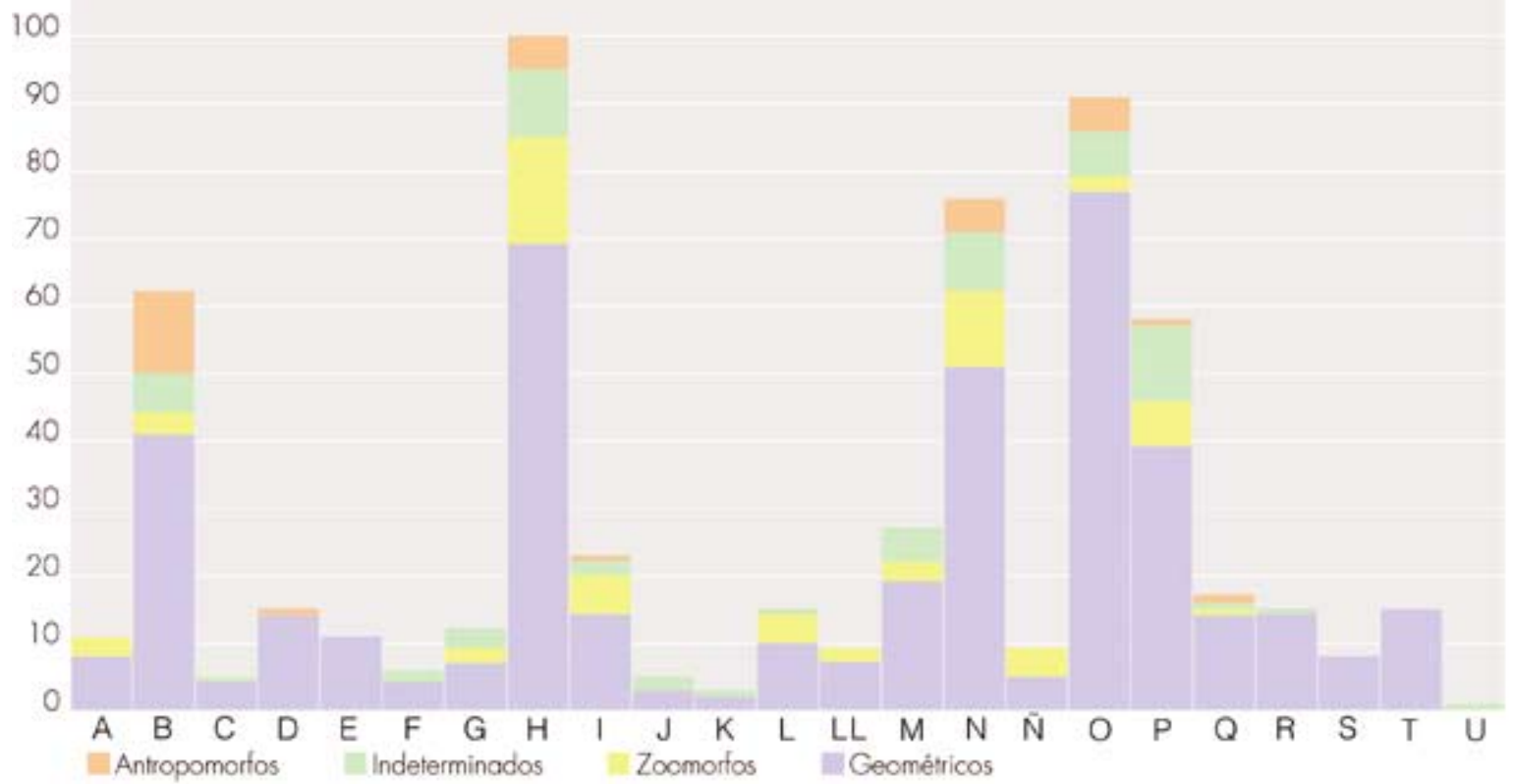

Gráfico 2. Gráfico comparativo de las cantidades relativas de motivos por panel.

Graph 2. Comparison of motif type and quantity in each panel. 
variedad de motivos, entre ellos: líneas rectas, rectángulos simples, cuadrados con divisiones internas, reticulados, espirales rectilíneos, líneas en zigzag, triángulos, grecas, trazos almenados simples, cruciformes de contorno rectilíneo, espigados, entre otros (fig. 8). Se registraron también líneas simples cortas, consideradas como motivos compuestos, dadas la proximidad y la articulación de elementos sin variación morfológica.

\section{Motivos indeterminados}

Fueron considerados aquí aquellos motivos que no pudieron ser nominados por carecer de morfologías definidas ni encontrarse repeticiones entre los mismos (fig. 9).

\section{Motivos figurativos}

\section{Zoomorfos}

Dentro de esta categoría se pueden reconocer dos subcategorías. La primera es la de huellas, como el motivo de los tridígitos, que estaría representando las huellas del suri u otra ave, motivo más ampliamente representado. En algunos casos, al igual que las líneas simples cortas, fueron considerados como motivos compuestos dada su proximidad. Otro motivo se asemeja a huellas de felino, realizado por la técnica de horadado. La segunda subcategoría corresponde a representaciones zoomorfas, con motivos que representan animales, como un posible motivo de cóndor, uno de serpiente y tres camélidos.

\section{Antropomorfos}

Se observó la presencia de tres motivos escutiformes o personajes con alguna vestimenta con escotaduras, estando ausentes los rasgos anatómicos (fig. 10). Un cuarto motivo, llamado por Quiroga el Gigante, es un antropomorfo de grandes dimensiones que presenta un tocado en forma de tumi y una vestimenta conformada por dos piezas, ambas decoradas con diseños geométricos. El rostro rectangular presenta ojos ovales con pupilas, nariz (o nariguera tipo triángulo invertido) y una pequeña boca (fig. 11). Otro motivo representa un personaje femenino de vientre abultado y vulva en forma de pequeño mortero con sus extremidades superiores orientadas hacia arriba como en acción de súplica, arenga o advertencia (fig. 12). Dentro de esta categoría dos motivos representan rostros humanos (fig. 12b). Por último, consideramos aquí una serie de motivos que denominamos enmarcados dado que puede tratarse de figuras humanas vistiendo unkus o petos rectangulares y subrectangulares, que presentan en su interior distintos motivos decorativos, de líneas cruzadas, puntos, trazos y cuadrados concéntricos, estando ausentes los rasgos anatómicos y contando en algunos casos con penachos a modo de tocados (fig. 13).

\section{ANÁLISIS DE LOS GRABADOS DE CHIQUIMI}

Para la interpretación de los grabados, Quiroga utilizó la información disponible sobre mitos locales, fuentes históricas (principalmente de los Andes Centrales) y el trabajo de indagación etnográfica con pobladores de la zona. No obstante, el supuesto de sincronía de los grabados condujo al autor a asumir a las representaciones como pertenecientes a un mismo momento narrativo y tomar a los diferentes paneles como una secuencia cronológica consecutiva dentro de la historia mítica, buscando una explicación dentro de dicha historia a los motivos considerados relevantes. ${ }^{10} \mathrm{El}$ siglo transcurrido desde la interpretación propuesta por Quiroga de las manifestaciones rupestres de la GCh nos permite, a la luz de la información arqueológica generada sobre distintos sitios, proponer nuevas alternativas explicativas.

Nuestra interpretación se fundamentará en el análisis de los motivos representados en los paneles de la GCh a partir de la comparación con imágenes similares presentes en otros sitios con arte rupestre del NOA y del norte chileno, así como en otros tipos de soporte material y las asignaciones cronológicas y simbólicas asociados a ellos.

Resulta útil detenernos aquí en dos términos teóricos valiosos: motivos y temas (Panofsky 1970). Los motivos nos remiten a los significados primarios o naturales, aquello que se desprende directamente de la observación de los diseños. Los objetos y los acontecimientos que estén representados por líneas, colores y volúmenes constituyen el mundo de los motivos, que se identifican sobre la base de la experiencia práctica (Panofsky 1970). En el arte rupestre, siguiendo a Gradín (1978: 120), entendemos el motivo como la "unidad de ejecución", es decir, figuras que puedan ser atribuidas a un "acto unitario de realización”. El tema refiere a los significados secundarios o convencionales, a la unión entre el significado primario y el concepto. El significado secundario difiere del primario en que es inteligible en vez de ser sensible. Esto se debe a que, como registros, los signos y estructuras creados por el hombre pueden expresar ideas separadas de los procesos de señalar y construir (Panofsky 1970). El motivo de la cruz, por ejemplo, está asociado al agua (tema) desde la interpretación 
Gruta de Chiquimí

Espirales rectilíneos
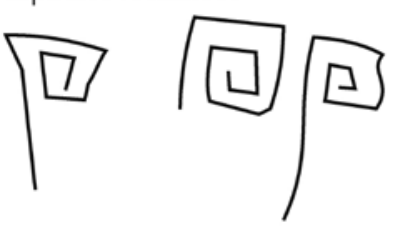

Líneas en zigzag

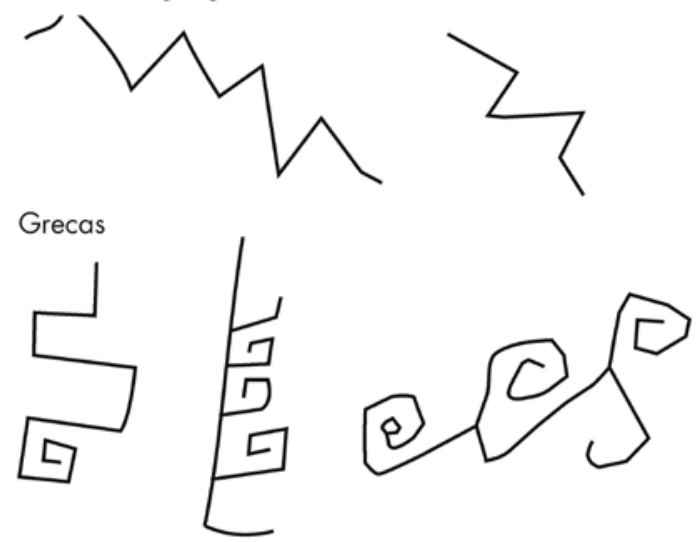

Cuadrados con divisiones internas
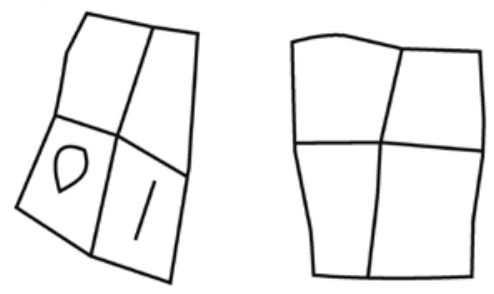

Trazos almendrados

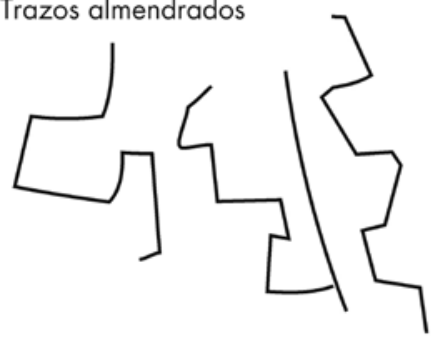

Cruciformes
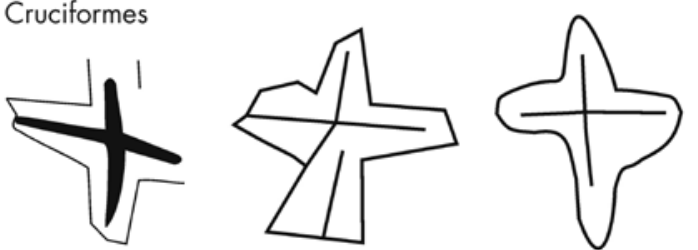

Otros
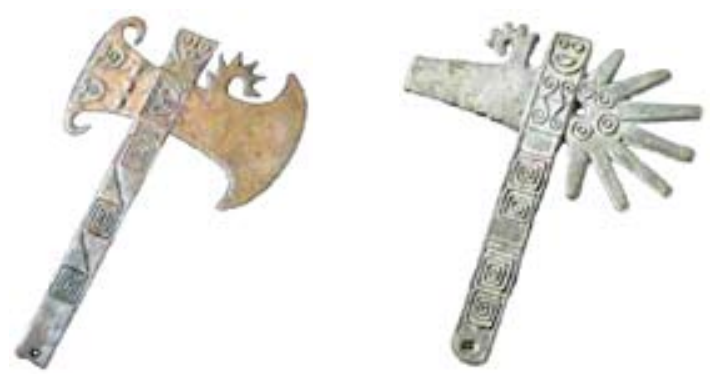

b. Hachas tardías
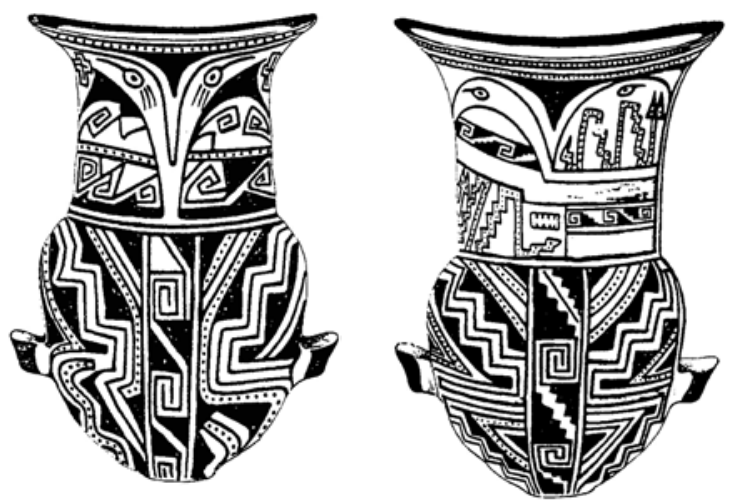

c. Urnas santamarianas

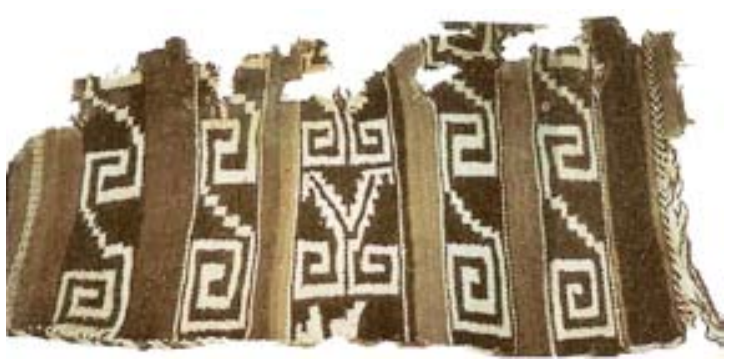

d. Textil de ajuar funerario

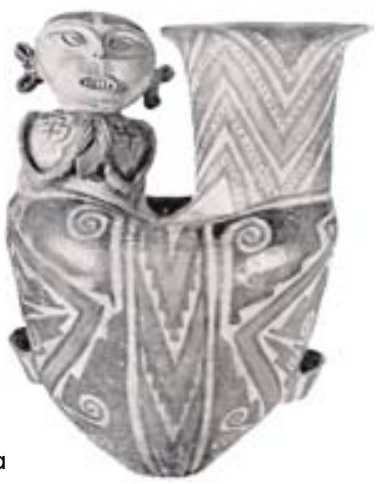

Figura 8. a) Ejemplos de motivos geométricos (sin relación de escala), Gruta de Chiquimí; b) Hachas tardías (González 2007: 39, fig. 8); c) Urnas del Período Tardío (González 1977: 329, fig. 289 y 290); d) Textil de Lorohuasi, Tinogasta, Catamarca (Renard 1999: 81, fig. 8) y e) Urna Quiroga del Período Tardío (González 1977: 335, fig. 294).

Figure 8. a) Examples of geometric motifs (not to scale), Chiquimi Grotto; b) Late Period axes (González 2007: 39, fig. 8); c) Late Period urns (González 1977: 329, figures 289 and 290); d) Textile from Lorohuasi, Tinogasta, Catamarca (Renard 1999: 81, fig. 8) and e) Late Period Quiroga urn (González 1977: 335, fig. 294). 


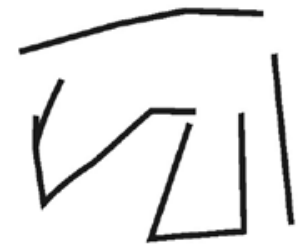

a

b
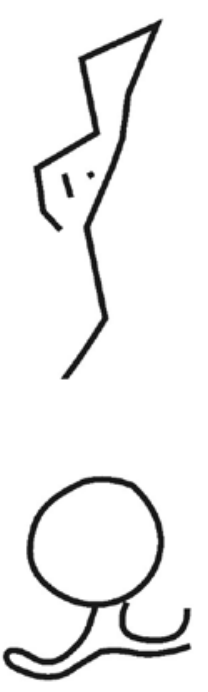

e
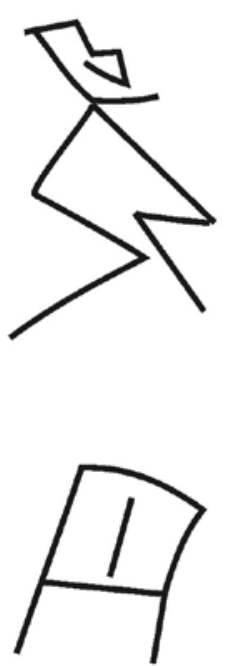

i f

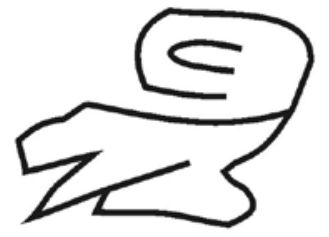

i

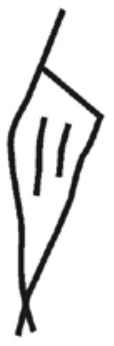

c

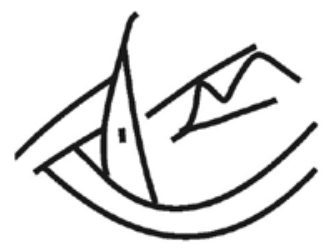

g

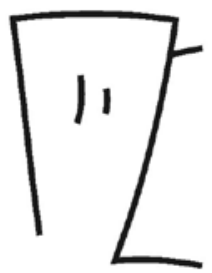

k

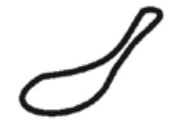

d
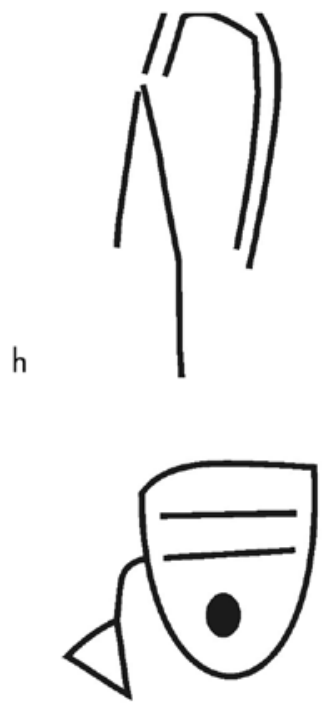

I

0

$20 \mathrm{~cm}$

Figura 9. Ejemplos de motivos indeterminados. a) Panel D; b) Panel L; c) Panel M; d, e, f, g y h) Panel O; i, j, k y l) Panel P. Figure 9. Unidentified motifs. a) Panel D; b) Panel L; c) Panel M; $d, e, f$, g and h) Panel $O ; i, j$, $k$ and l) Panel P.

de Quiroga (1899), y, por lo tanto, a la fertilidad como significado intrínseco.

Al hablar de significados estamos considerando implícitamente que todo arte rupestre es un sistema visual/espacial de comunicación, una realidad semiótica, constituyéndose en un producto social, histórico y contingente (Troncoso 2005a). En el momento de ejecución de los grabados, se pone en acción el conjunto de normas sociales y principios vigentes para comunicar un aspecto de la realidad (Troncoso 2005b). En otras palabras, el arte rupestre constituye la evidencia de un espacio a través del cual se transmiten mensajes, donde por medio de un sistema codificador se reiteran los temas importantes de las comunidades del pasado (Ledesma 2006-2007). Así, las imágenes visuales cobran sentido únicamente en el marco de los códigos semióticos, de las convenciones sociales que las produjeron.

A base del análisis previo y a los motivos definidos en el apartado anterior expondremos aquí una interpretación preliminar de los grabados de Chiquimí. Para ello retomamos el concepto de tema (Tarragó et al. 1997: 228), así como las interpretaciones realizadas por diversos autores a lo largo de los estudios de arte rupestre del NOA.

Con respecto a los motivos geométricos, muchos de los cuales Quiroga interpretara como símbolos meteorológicos, es difícil acceder al significado que pudieron haber tenido para sus productores. Estos motivos, como por ejemplo los cruciformes y las líneas en zigzag, aparecen ampliamente representados en numerosos sitios con arte rupestre del NOA, en paneles asignados tanto a tiempos tempranos como tardíos. En Yocavil aparecen también materializados en otro soporte abundante como es la cerámica. En este sentido es válido remarcar la similitud de algunos motivos (espigados, líneas en zigzag, cruz) de la GCh con diseños presentes en el interior de pucos pretardíos grabados poscocción encontrados en Soria 2 (Spano 2010: 843, figura 4). No obstante, la mayoría 


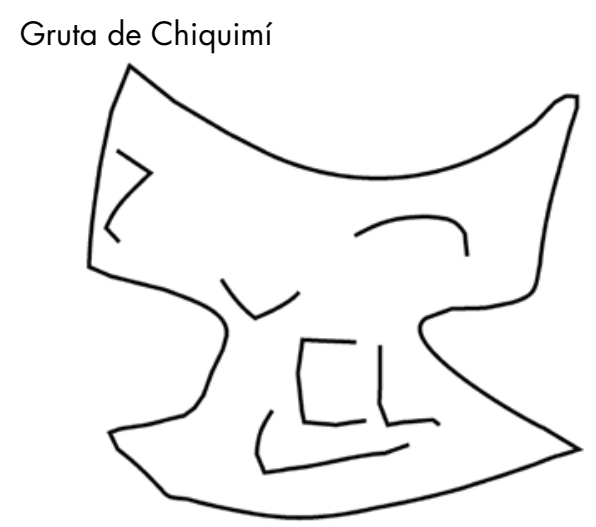

0

$10 \mathrm{~cm}$

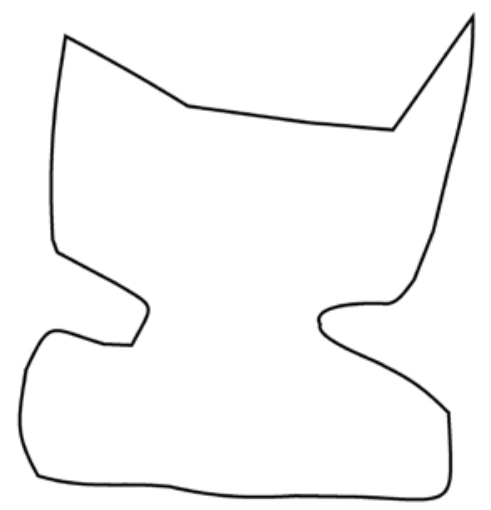

0

$5 \mathrm{~cm}$

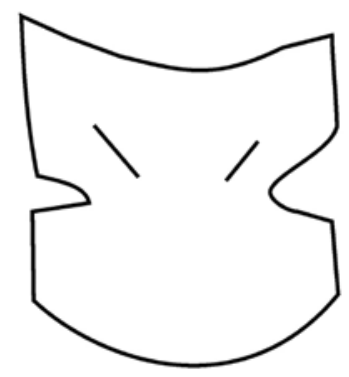

a.

0

$3 \mathrm{~cm}$
Otros

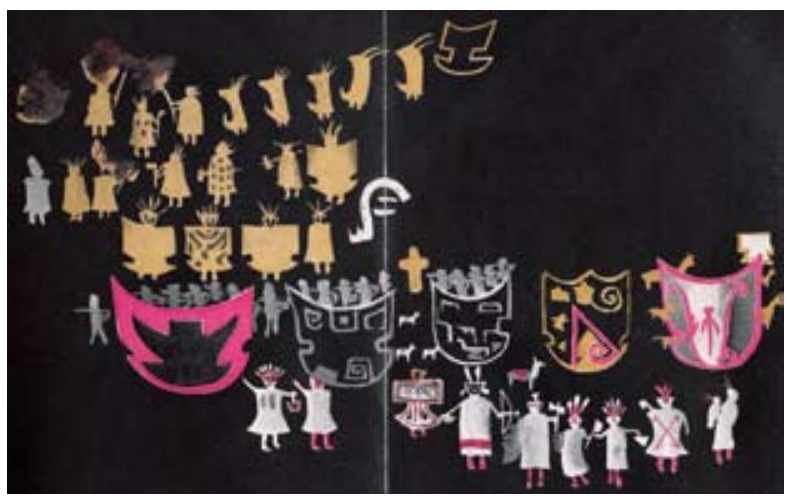

b.
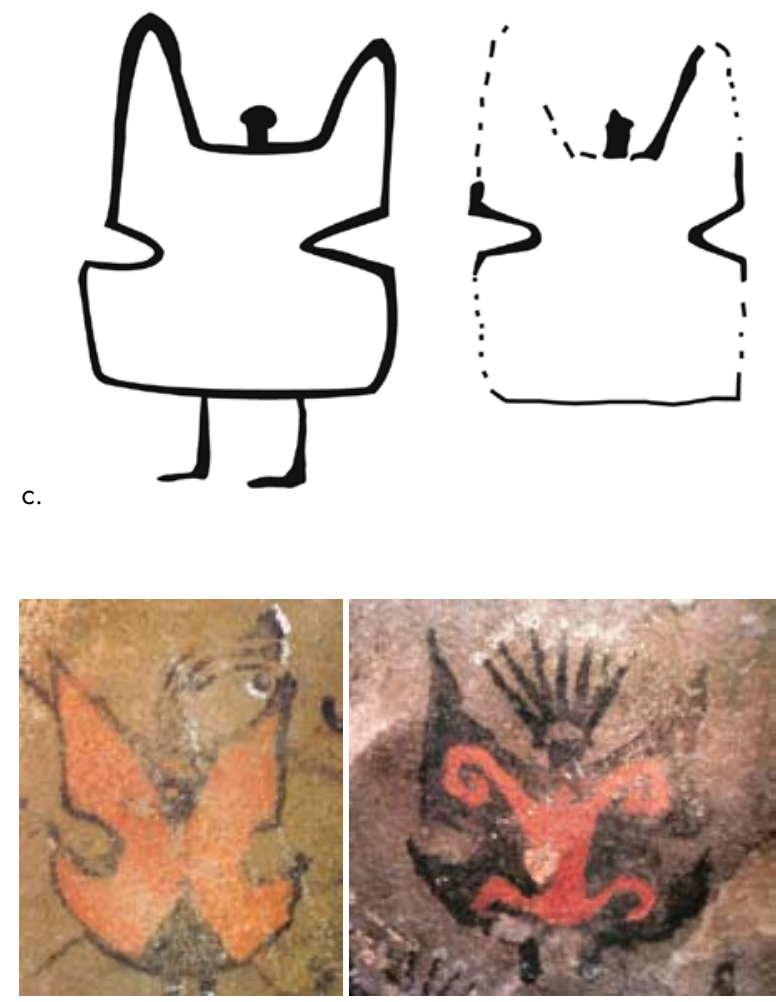

d.

Figura 10. a) Escutiformes, Gruta de Chiquimí; b) Carahuasi, Salta (Quiroga 1931, fig. 209); c) Casas Viejas, Antofagasta de la Sierra, Catamarca (Aschero 2000: 34, fig. 19) y d) Cerro Cuevas Pintadas, Salta (Podestá et al. 2005, láminas 16 y 20).

Figure 10. a) Shield shapes, Chiquimí Grotto; b) Carabuasi, Salta (Quiroga 1931, fig. 209); c) Casas Viejas, Antofagasta de la Sierra, Catamarca (Aschero 2000: 34, fig. 19) and d) Cerro Cuevas Pintadas, Salta (Podestá et al. 2005, plates 16 and 20). 


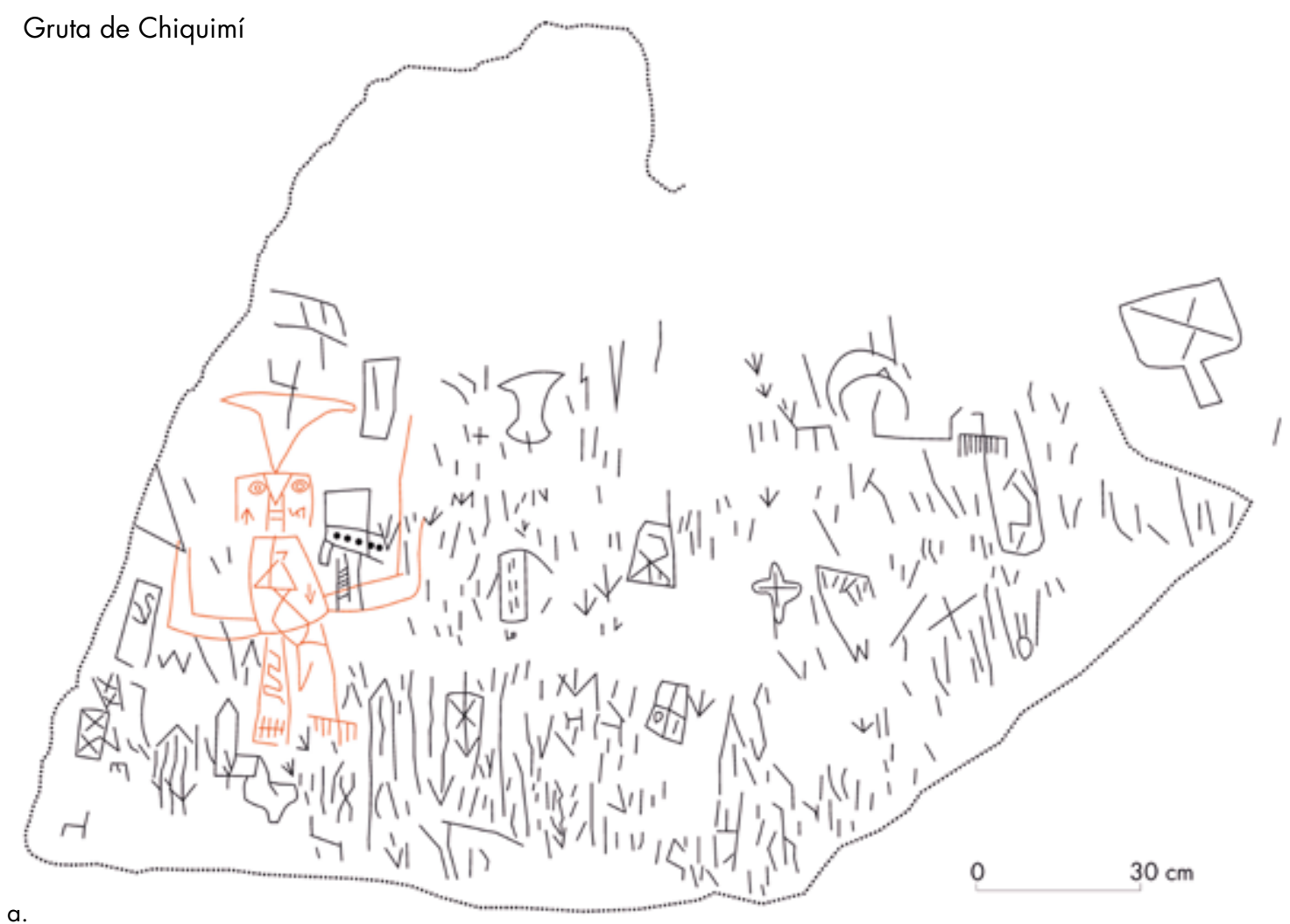

\section{Otros}

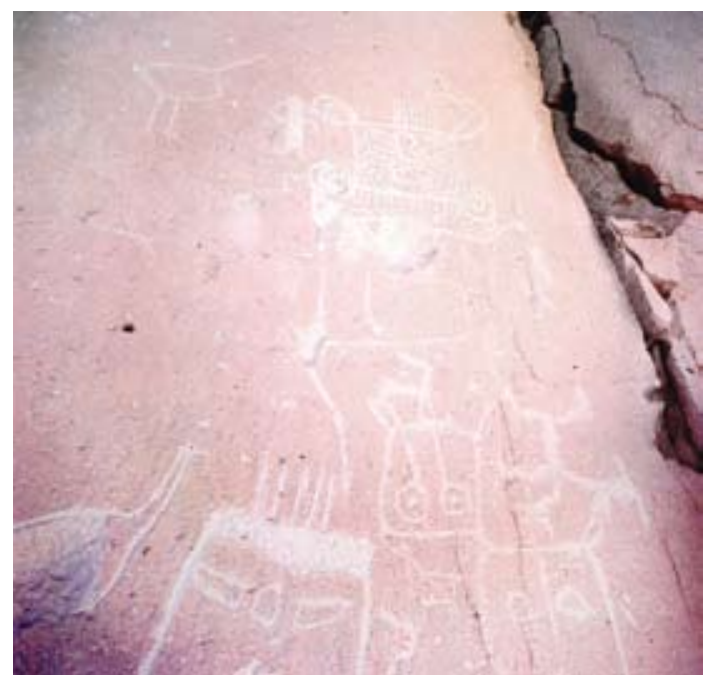

b. Mascariformes grabados

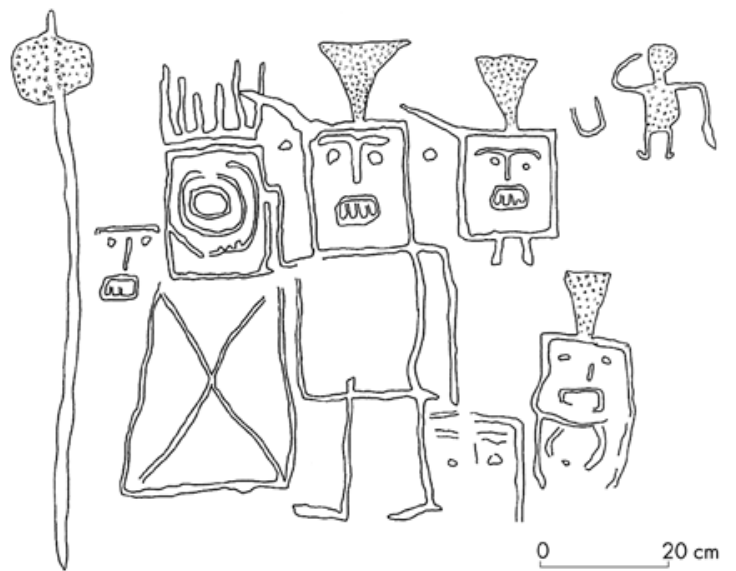

c. Antropomorfos grabados

Figura 11. a) Panel H, en rojo el motivo del Gigante, Gruta de Chiquimí; b) Punta del Pueblo, Antofagasta de la Sierra, Catamarca (Aschero 1999: 120) y c) Purilacti 1, Salar de Atacama, Chile (Cartajena \& Núñez 2006: 228, fig. 7).

Figure 11. a) Panel H, with Giant motif in red, Chiquimi Grotto; b) Punta del Pueblo, Antofagasta de la Sierra, Catamarca (Aschero 1999: 120) and c) Purilacti 1, Salar de Atacama, Chile (Cartajena \& Núñez 2006: 228, fig. 7). 
a.
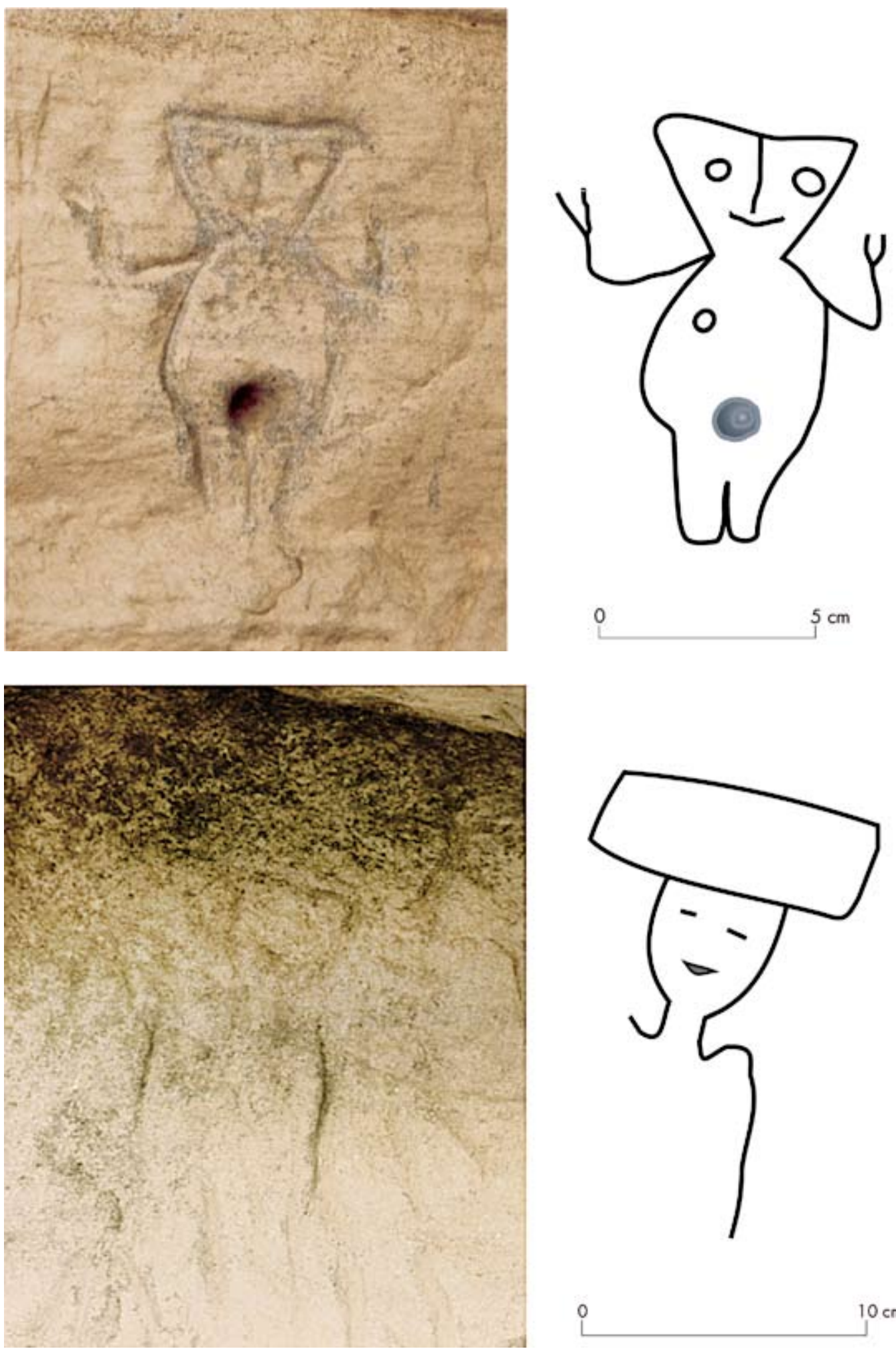

0 $10 \mathrm{~cm}$

Figura 12. a) Antropomorfo de vientre abultado y vulva en forma de pequeño mortero; b) Antropomorfo indeterminado. Figure 12. a) Human figure with exaggerated abdomen and mortar-shaped vulva; b) Unidentified human figure. 
Gruta de Chiquimí
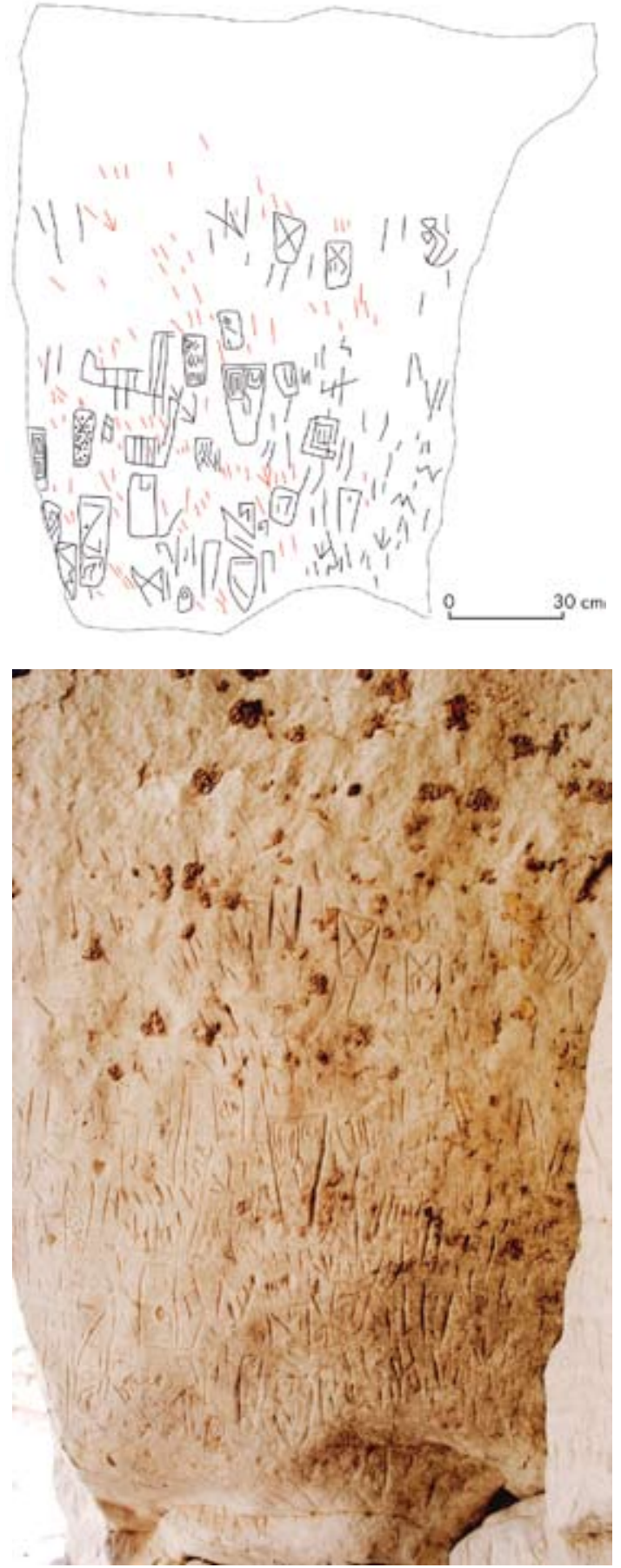

a.
Otros

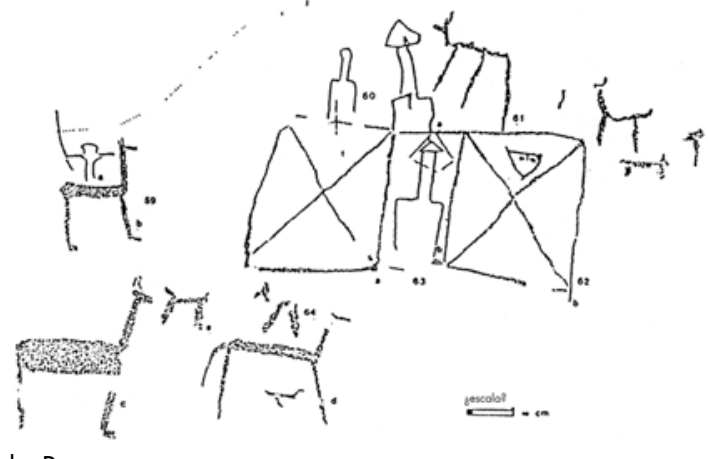

b. Petos

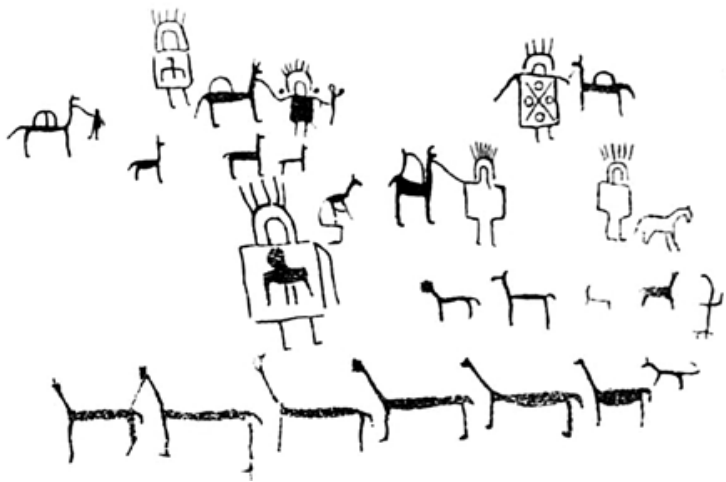

c. Personajes con petos y túnicas
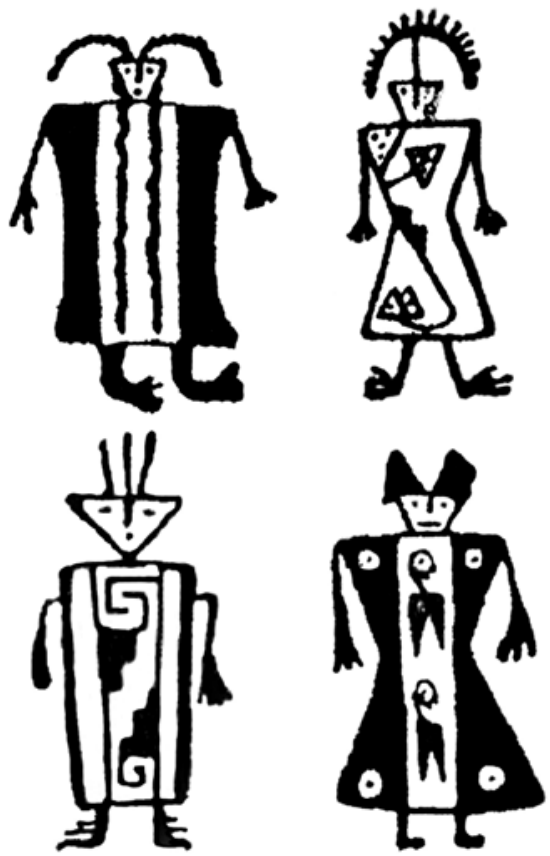

d. Personajes santamarianos

Figura 13. a) Panel B con los Enmarcados, en rojo líneas simples cortas, Gruta de Chiquimí; b) Punta del Pueblo, Antofagasta de la Sierra, Catamarca (Podestá 1989: 47, fig. 12); c) Rinconada de Santa Bárbara, Chile (Berenguer 1999: 39) y d) Personajes de urnas santamarianas (Quiroga 1992, fig. 212, primeros tres personajes, fig. 86, último personaje).

Figura 13. a) Panel B with 'framed' motifs and short lines marked in red, Chiquimí Grotto; b) Punta del Pueblo, Antofagasta de la Sierra, Catamarca (Podestá 1989: 47, fig. 12); c) Rinconada de Santa Bárbara, Chile (Berenguer 1999: 39) and d) Figures from Santa Maria urns (Quiroga 1992, first three figures from Figure 212, final figure from Figure 86). 
de estos motivos geométricos (fig. 8a) aparece también en estilos tardíos, principalmente en la iconografía santamariana, tanto en la cerámica como en una variedad de soportes (figs. 8b, c, d, e).

La línea en zigzag ha sido asociada con Inti-Illapa, el Relámpago, la serpiente rayo, presente en las urnas funerarias santamarianas (Quiroga 1931; Nastri 2006). Los motivos asociados a la serpiente (líneas ondulantes) han sido vinculados a los cultos agrarios y a la fertilidad de la tierra (Fiadone 2003). La serpiente también se halla presente como motivo decorativo en los discos de bronce santamarianos, apareciendo como guardas perimetrales o como motivos exclusivos de las piezas, marcando una continuidad con los rasgos inconográficos de Aguada (González, L. 2007). Otro rasgo de conexión entre los grabados y la metalurgia prehispánica de momentos tardíos, es la aparición de grecas y espirales en los mangos y talones de las hachas (fig. 9b) y en las campanas ovales (González, L. 2007).

Los motivos de enmarcados que presentan en su interior distintos diseños decorativos (fig. 13a) pueden tratarse, como mencionamos, de figuras humanas vistiendo unkus o petos de cuero, si se hubiese efectuado una operación de abstracción (Arnheim 1985). ${ }^{11}$ Si esta interpretación es correcta, se asemejaría a la propuesta por Aschero (2000) para el arte rupestre de Antofagasta de la Sierra y zonas aledañas. Para los momentos tardíos las representaciones de jefes o curacas, o en muchos de los casos de los atributos indicadores del poder que portan, adquieren un papel central; "así la representación de figuras humanas escutiformes como hachas, de tumis de doble filo o de ciertos ornamentos pectorales o cefálicos, se convierte en una forma de metáforas visuales de ese poder [...]" (Aschero 2000: 18). A su vez, la presencia de dichos antropomorfos puede ser considerada un marcador temporal, asignando las representaciones al Período Desarrollos Regionales dada su presencia en la iconografía santamariana (Aschero 2000: 19) (fig. 13d). Estaría favoreciendo esta interpretación que tanto en el arte rupestre del NOA como en el río Loa las representaciones de petos y unkus exhiben una amplia variabilidad, siendo algunos altamente elaborados como los de Carahuasi y cerro Cuevas Pintadas (Salta) (figs. 10b, c, d) (Ambrosetti 1895; Boman 1908; Aschero 2000), mientras otros tienden a ser esquemáticos como los presentes en Punta del Pueblo en Antofagasta de la Sierra, Catamarca (Podestá 1989: 47; fig. 12) o los de la Rinconada de Santa Bárbara en el Alto Loa (Berenguer 1999, 2004; figs. 13b, c).

Los escutiformes se asemejan por su forma a personajes y escudos encontrados tanto en Cafayate, en el sitio Alero con Morteros (Ledesma 2006-2007) de momentos tardíos, como en la gruta de Carahuasi y en alero Ambrosetti del cerro Cuevas Pintadas (Salta), asignados estos últimos a momentos inkaicos. Uno de ellos se asemeja también a los escutiformes del sitio Casas Viejas en Antofagasta de la Sierra, Catamarca, que responden al patrón $H 4 b$ definido por Aschero (2000: 32), siendo semejantes a los escutiformes presentes en las urnas y en los discos de bronce santamarianos, piezas contemporáneas a la presencia inka en la región (fig. 10). Escudos de este tipo, con o sin rasgos del cuerpo humano, fueron probablemente figuras de alto poder alegórico y, como sugiere Aschero (2000: 36), pudieron operar como emblemas o marcas étnicas en el paisaje, utilizadas como "estrategias simbólicas para resignificar objetos de prestigio o para transferir, en la imagen visual, el poder del objeto al individuo". Como notan Podestá y colaboradores (2005: 39), los escudos en muchos casos sobresalen entre otros motivos debido a su especial diseño, mayor tamaño, policromía o su posición más destacada en los soportes rocosos, características que les suelen otorgar mayor visibilidad.

Con respecto a la figura que Quiroga (1931: 38) ha descrito como "[...] ese tipo sui géneris de gigante con un casquete fálico", sus rasgos parecen remontarse a momentos de la iconografía Aguada (fig. 11). Esta semejanza se centra en la presencia de una cabeza rectangular, similar en personajes Aguada visibles en otros soportes rocosos (fig. 11b). De la misma forma, presenta similitudes en el diseño con los personajes encontrados en el panel II del sitio Purilacti 1, en la cuenca del salar de Atacama del norte de Chile (fig. 11c; Cartajena \& Núñez 2006). Comparte con ellos el rostro cuadrangular, la boca rectangular, el tocado cefálico similar a un penacho en forma de triángulo invertido y una tendencia a la geometrización. Los autores plantean que la ocupación del sitio se habría dado durante la Tradición San Pedro, cuando las redes caravaneras de larga distancia establecieron relaciones con el altiplano nuclear (Tiwanaku) y los valles del Noroeste Argentino (durante momentos Aguada; Cartajena \& Núñez 2006). De este modo, las semejanzas estilísticas con los antropomorfos de Purilacti 1 estarían reforzando una cronología para el Período Medio del Gigante de Chiquimí.

Según algunos autores (Aschero \& Korstanje 1996), las sociedades donde aparece este tipo de iconografía (presencia de personajes con tocados, con dimensiones superiores al resto de los motivos) son aquellas en las que la producción agrícola ya juega un papel de mayor peso socioeconómico y donde la figura del jefe toma relevancia como organizador social. Cada uno de estos 
indicios denota distinciones de estatus, en sociedades con mayor diferenciación social y laboral (Cartajena \& Núñez 2006).

De los restantes antropomorfos, el personaje de vientre abultado y vulva en forma de pequeño mortero con sus extremidades superiores orientadas hacia arriba fue vinculado a la Pachamama (Quiroga 1931: 45). Aschero (2007) refuerza esta idea al caracterizar los personajes femeninos como símbolos de fertilidad. Si bien es difícil una asignación cronológica de dicho motivo, es llamativa su semejanza con un antropomorfo femenino con los brazos hacia arriba, el vientre abultado y el órgano femenino marcado en forma de triángulo registrado por Ambrosetti (1897: 66, figura 45) en el petroglifo de las Cañas, en la región del poblado tardío de Quilmes.

Dentro de los motivos zoomorfos, los camélidos pueden tratarse de llamas del patrón $H 3$ definido por Aschero (2000: 29), caracterizado por una esquematización geométrica rectilínea y lineal. Este grado de estandarización ocurre durante los Desarrollos Regionales o el Intermedio Tardío (secuencia del Loa) en asociación a las figuras con unkus o petos de cuero y las figuras con forma de escudo (Aschero 1999: 125, y Le Paige 1965 en Berenguer 2004). Ejemplos de estos motivos se encuentran también en el sector A del Alero de los Brujos, en el Pukara de Rinconada (Ruiz \& Chorolque 2007). Por otra parte, podemos mencionar que ese tipo de morfología de camélidos ha sido definida como un canon característico de la microrregión de Cafayate (Ledesma 2006-2007) para el Período Desarrollos Regionales. En el caso de la GCh, solo se han podido contabilizar tres camélidos, los cuales responden a este patrón, encontrándose aislados y sin relación aparente con los antropomorfos.

En resumen, si bien las técnicas de producción y las escasas superposiciones no muestran diferencias que pueden ser asignadas a distintos momentos de ejecución, las interpretaciones a base de los motivos parecen indicar que estos no son necesariamente contemporáneos. Inicialmente podemos asegurar una producción durante las etapas tardías del período agroalfarero, avalada por los motivos escutiformes, los personajes con unkus y las llamas rectilíneas. Por su parte, el Gigante y las huellas de felinos podrían adjudicarse por semejanzas estilísticas a una manifestación precedente con influencias del fenómeno conocido como Aguada. Finalmente, no podemos descartar la posible realización de imágenes durante las etapas tempranas del período agroalfarero, p. e., las abundantes figuras geométricas e indeterminadas simples, que se muestran semejantes con la alfarería formativa de la zona.

\section{LA GRUTA EN CONTEXTO}

A la hora de considerar la funcionalidad de la GCh y sus grabados, nuestra interpretación se basará preliminarmente en los motivos y sus cronologías, así como en la ubicación de la GCh en el paisaje. De esta manera, daremos cuenta de las diferentes funciones que pudo desempeñar el arte rupestre en la construcción del espacio, y su inserción dentro de los procesos sociales, dado que la configuración del paisaje y las estrategias visuales de una sociedad responden a su situación histórica particular (Troncoso 2005b).

Como comentamos en el apartado anterior, la GCh se encuentra ubicada en una de las quebradas del este, subsidiarias al valle de Santa María. La quebrada se conforma a partir de la presencia de murallones de arenisca que delimitan las terrazas altas que se adosan a los faldeos de la sierra del Aconquija. Esta localización vuelve a la GCh un lugar de manifestaciones rupestres accesible pero apartado, por ser un espacio de baja visibilidad y visibilización (Criado Boado 1993), situación espacial que llevó a Quiroga a plantear el carácter de "santuario" del sitio. Pensando en los posibles contextos de uso de la misma, debemos mencionar que los grabados se encuentran a poco más de $2 \mathrm{~km}$ en línea recta de la LRS y a menos de $1,5 \mathrm{~km}$ en línea recta de Soria 2 en la meseta de Andalhuala, sitios anteriormente mencionados, considerados zonas residenciales y de explotación económica. Es posible imaginar, entonces, que la GCh pudo ser visitada por los pobladores locales en diversas ocasiones durante un período cronológico prolongado.

En el paisaje semiárido del valle, las quebradas subsidiarias son principales fuentes de agua con las que debieron contar en el pasado personas y animales. De esta manera la localización de los grabados a la vera de un cauce nos puede estar hablando de la importancia de la marcación de este recurso hídrico en el paisaje. Motivos como las líneas en zigzag, la cabeza de serpiente y el antropomorfo femenino con vientre abultado apuntan a la importancia de la fertilidad de la tierra. El emplazamiento en proximidad de un cauce estacional, que solo transporta agua cuando es alimentado por las lluvias, hace de la GCh un lugar propicio para los pedidos de agua, siendo las respuestas a esos pedidos materializadas sobre el mismo cauce. Al estar ubicada en el interior de una quebrada que termina en los faldeos del Aconquija, se tendrían que realizar incursiones específicas para producir y apreciar los grabados.

De esta manera, pensar en manifestaciones que serían de conocimiento y uso estrictamente locales, dado su ocultamiento de la mirada de los foráneos, puede implicar el uso del arte como medio para expresar "la realidad 
manifestada por sus productores en forma particular" (Ruiz \& Chorolque 2007: 37). Estos grabados podrían estar reflejando mensajes vinculados a secuencias de esa realidad social, como la necesidad del agua para la continuidad de la vida o la expresión de las tensiones sociales de grupos locales entre sí o posteriormente relacionadas a la llegada -efectiva o percibida mediante la información circulante- del Inka.

En este sentido, la presencia de escutiformes y personajes ataviados con unkus nos lleva a pensar que la violencia, aunque sea simbólica, haya estado presente como tema en la GCh. Nastri (2005) sostiene que los guerreros reconocibles en las urnas santamarianas tardías están expresamente vinculados a una ideología militarista. Otras evidencias arqueológicas, como la presencia de figuras de guerreros y cabezas cercenadas en placas metálicas, el uso de hachas y escudos y la construcción de asentamientos fortificados, también apuntan a un posible conflicto social endémico (Tarragó 2000).

Si iconográficamente, como plantean Ruiz y Chorolque (2007: 150) para Rinconada, los grabados reflejan la temática de "[...] la identidad y etnicidad entendiendo a la identidad como un reconocimiento de las semejanzas y las diferencias y a la etnicidad justamente como poder reconocer en forma colectiva esas diferencias", es factible que en la GCh se esté manifestando un fenómeno semejante, dando cuenta de relaciones de identidad y etnicidad. Estas relaciones pudieron estar marcadas por ese estado de conflicto social endémico, posiblemente relacionado a problemas de índole productivo (González \& Pérez Gollán 1966; Bouysse-Cassagne \& Harris 1987). Situación que parece plasmada en la GCh, debido a la representación conjunta de motivos asociados al tema de la fertilidad con motivos que dan cuenta del conflicto, quedando plasmados en los grabados las diferentes características y atuendos, íconos de los distintos grupos locales.

Con relación a los motivos de reminiscencia Aguada (Gigante, huellas de felino), los mismos pueden estar indicando el uso de la GCh en momentos previos a la situación antes planteada. Las manifestaciones del fenómeno Aguada en Yocavil no son aún del todo claras, aunque ciertas evidencias dan cuenta de una posible participación en esa esfera de interacción (Tarragó et al. 1988; Williams 2003; Nastri et al. 2009). Otra posible interpretación del tema felínico en Yocavil fue recientemente planteada por Reynoso y Pratolongo (2008). Estos autores han propuesto que motivos del llamado "complejo felínico", que desaparecen del repertorio iconográfico en Yocavil hacia fines del 1000 DC, reaparecen cuatrocientos años más tarde resignificados en la iconografía santamariana. Estos motivos surgen llamativamente en las urnas fases IV y $\mathrm{V}$ asociados a los motivos de escutiformes y unkus, de momentos finales del Período Tardío, coincidiendo con la ocupación inkaica de Yocavil. Al resignificarse a fines del Período Tardío, el complejo felínico pudo ser identificado con la jerarquización, la desigualdad entre sectores y el conflicto,

[...] aunque por el momento no hay forma de establecer claramente si estos cambios en la iconografía responden a factores ligados con la ocupación inkaica en la región, o bien a situaciones locales previas que pudieron haberse acentuado durante la conquista inkaica (Reynoso \& Pratolongo 2008: 93).

\section{PALABRAS FINALES}

Este trabajo tuvo como objetivo principal presentar los grabados de la gruta de Chiquimí, retomando los valiosos aportes de los antiguos trabajos de Adán Quiroga, a la luz de los nuevos conocimientos generados por los estudios de arte rupestre. Las conclusiones aquí arribadas, de carácter preliminar, plantean a la GCh como un lugar relativamente oculto, con motivos que apuntan a una producción local y un uso principalmente en el Período Agroalfarero Tardío, aunque no se descarta que este espacio haya sido significativo para los momentos pretardíos.

Los grabados de la gruta de Chiquimí parecen ser expresiones únicas del arte rupestre, siendo su análisis un aporte para los estudios de dichas manifestaciones en el NOA al mostrar tanto motivos novedosos (v. g. Gigante, la figura humana femenina), como variantes de motivos ya conocidos (p. e., escutiformes, motivos geométricos, zoomorfos). En lo que respecta al valle de Yocavil, la relocalización de la gruta de Chiquimí abre una nueva posibilidad de acceder a una materialidad escasamente investigada, que aporta un novedoso corpus de información que enriquecerá las actuales y futuras investigaciones arqueológicas en el valle.

RECONOCIMIENTOS A Walter Fregenal por sus recorridos por la localidad de Entre Ríos que permitieron dar con la gruta de Chiquimí. A María de Hoyos y María Mercedes Podestá y equipo por sus ideas y consejos a la hora de la interpretación de los grabados. A Sonia Lanzelotti y Marcelo Lamamí por parte del registro fotográfico de los grabados. A Luis González, Alejandra Reynoso y Valeria Palamarczuk por la lectura crítica de este trabajo. A Myriam Tarragó por la revisión del artículo, su constante apoyo y consejos. A los evaluadores anónimos del manuscrito que mejoraron sin duda la calidad del mismo. Deseamos agradecer también el apoyo económico del Fondo Nacional de las Artes que posibilitó las tareas realizadas. Todo lo expuesto en este trabajo es de exclusiva responsabilidad de los autores. 


\section{NOTAS}

${ }^{1}$ Este trabajo fue realizado en el marco de los proyectos UBACYT 029 y CONICET PIP 6148 del Proyecto Arqueológico Yocavil.

${ }^{2}$ Para el valle de Yocavil la cerámica es uno de los materiales más abundantes, siendo escasa la presencia de otros soportes, como los textiles.

${ }^{3}$ La localidad de Entre Ríos es conocida en la literatura arqueológica de la región también como Shiquimil, sin embargo mantendremos aquí la escritura de Quiroga (Chiquimí) para no sumar confusiones.

${ }^{4}$ En mayo de 1995, Susana Renard, Inés Maldonado, Mónica Piñeiro, Myriam Tarragó y un grupo de seis estudiantes, en compañía de Silvia González de Santa María, prospectaron la quebrada de Shiquimil en búsqueda de la gruta, pero no pudo ser ubicada.

${ }^{5}$ Iconografía hoy atribuida al fenómeno arqueológico de La Aguada.

${ }^{6}$ El mito de Huayrapuca es básicamente sobre la fertilidad de los campos y los animales.

${ }^{7}$ Anteriormente había planteado que Inti-Illapa, El Relámpago, era aliado de Huayrapuca en la lucha contra El Nublado, al cual dispersa cuando sopla en la tormenta.

${ }^{8}$ Quiroga (1931: 39) compara este símbolo con el que presenta Yanqui Pachacuti en su plancha.

${ }^{9}$ La prospección, a cargo de los autores, se realizó entre los días 03/03/2008 y 15/03/2008 en el marco de las tareas de investigación para la tesis de licenciatura de Alina Álvarez Larrain.

${ }^{10}$ Consideramos que hay motivos que, dada su buena visibilidad aun actualmente, como las huellas de suri, Quiroga optó por no integrar a su relato del mito de Huayrapuca.

11 Arnheim (1985: 171) considera que "el arte de dibujar lo esencial de una especie dada de entidad, puede aplicarse solo a totalidades organizadas en las que algunos rasgos ocupan posiciones clave mientras que otras son secundarias o accidentales". Los enmarcados, entonces, serían antropomorfos donde el rasgo clave es la vestimenta ( $u n k u)$, no siendo necesaria la ejecución de sus rasgos anatómicos.

\section{REFERENCIAS}

Álvarez M.; D. Fiore, E. Favret, R. Castillo Guerra \& P. Bozzano, 1998 Ms. Identificación de artefactos y técnicas empleados en la producción de grabados rupestres mediante la observación y el análisis de rastros de uso en artefactos experimentales y de surcos grabados de motivos experimentales. Informe para el Proyecto Arqueológico Yocavil.

Álvarez Larrain, A., 2009. Teledetección y análisis del uso del espacio en el sudeste del valle de Yocavil (Dpto. de Santa María, Prov. de Catamarca). Tesis de Licenciatura en Ciencias Antropológicas (orientación en Arqueología), Facultad de Filosofía y Letras, Universidad de Buenos Aires.

— 2010. Arquitectura y paisajes en la localidad arqueológica de Andalhuala (valle de Yocavil, Catamarca). Revista del Museo de Antropología 3: 33-48, Córdoba.

Álvarez larrain, A.; J. Baigorria, C. Bellotti, J. P. Carbonelli, S. Grimoldi, S. López, D. Magnifico, V. Palamarczuk, R. Spano, G. Spengler, L. Stern Gelman \& F. Weber, 2009. Avances en el estudio de un contexto doméstico formativo en el valle de Yocavil. En Entre pasados y presentes II. Estudios contemporáneos en Ciencias Antropológicas, T. Bourlot, D. Bozzuto, C. Crespo, A. C. Hecht \& N. Kupersmit, Eds., pp. 369-383. Buenos Aires: Vázquez Mazzini Editores.

Ambrosetti, J. B., 1895. Las grutas grabadas y los petroglifos de la provincia de Salta. Boletín del Instituto geográfico argentino, Tomo XVI, cuadernos 5 a 8, Buenos Aires.

-1897. La antigua ciudad de Quilmes (valles calchaquíes). Boletín del Instituto Geográfico Argentino 18: 33-70, Buenos Aires.
ARNheIM, R., 1985. El pensamiento visual. Buenos Aires: EUDEBA. Aschero, C., 1988. Pinturas rupestres, actividades y recursos naturales, un encuadre arqueológico. En Arqueología contemporánea argentina, H. Yacobaccio, Ed., pp. 51-69. Buenos Aires: Búsqueda.

— 1999. El arte rupestre del desierto puneño y el Noroeste Argentino. En Arte rupestre en los Andes de Capricornio, J. Berenguer \& F. Gallardo, Eds., pp. 97-134. Santiago: Museo Chileno de Arte Precolombino.

- 2000. Figuras humanas, camélidos y espacios en la interacción circumpuneña. En Arte en las rocas: Arte rupestre, menhires $y$ piedras de colores en Argentina, M. M. Podestá \& M. de Hoyos, Eds., pp. 15-44. Buenos Aires: Sociedad Argentina de Antropología, AINA.

— 2007. Iconos, huancas y complejidad en la Puna Sur argentina. En Producción y circulación prebispánicas de bienes en el sur andino, A. E. Nielsen, M. C. Rivolta, V. Seldes, M. M. Vázquez \& P. H. Mercolli, Eds., pp. 135-167. Córdoba: Editorial Brujas.

Aschero, C. \& M. A. Korstanje, 1996. Sobre figuraciones humanas, producción y símbolos. Aspectos del arte rupestre del NOA. En Volumen del XXV aniversario del Museo Arqueológico Dr. Eduardo Casanova, M. C. Rivolta, Ed., pp. 13-41. Tilcara: Instituto Interdisciplinario, Universidad de Buenos Aires.

BAigorria, J. \& R. SPANO, 2007. Análisis preliminar de la cerámica del sitio formativo Soria 2 (Valle de Yocavil, Catamarca). En Actas del XVI Congreso Nacional de Arqueología Argentina, III, pp. 65-70. San Salvador de Jujuy: Universidad Nacional de Jujuy.

Belotti, C., 2007. Consumo de camélidos en el valle de Yocavil (Provincia de Catamarca) a inicios del Período Formativo, fines del primer milenio AC: zooarqueología del sitio Soria 2. En Actas del XVI Congreso Nacional de Arqueología Argentina, III, pp. 85-89. San Salvador de Jujuy: Universidad Nacional de Jujuy.

Berenguer, J., 1999. El evanescente lenguaje del arte rupestre en los Andes atacameños. En Arte rupestre en los Andes de Capricornio, J. Berenguer \& F. Gallardo, Eds., pp. 9-56. Santiago: Museo Chileno de Arte Precolombino.

- 2004. Cinco milenios de arte rupestre en los Andes atacameños: Imágenes para lo humano, imágenes para lo divino. Boletín del Museo Chileno de Arte Precolombino 9: 75-108.

Boman, E., 1908. Antiquités de la Région Andine de la République Argentine et du désert d'Atacama, tomo I, pp. 81-197. Paris: Imprimerie Nationale.

Bouysse-Cassagne, T. \& O. Harris, 1987. Pacha: en torno al pensamiento Aymara. En Tres reflexiones sobre el pensamiento andino, J. Medina, Ed., pp. 11-59. La Paz: Hisbol.

Bruch, C., 1911. Exploraciones arqueológicas en las provincias de Tucumán y Catamarca. Revista del Museo de la Plata XIX: 1-209.

Bugliani, F., 2008. Consumo y representación en el Formativo del sur de los valles calchaquies (Noroeste Argentino). Los conjuntos cerámicos de las aldeas del primer milenio $A D$. BAR International Series 1774. Oxford: BAR.

CARBONELLI, J. P., 2009. Interacciones cotidianas entre materias primas y sujetos sociales en el valle de Yocavil. El caso del sitio Soria 2 (Andalhuala, Provincia de Catamarca). Tesis de licenciatura en Ciencias Antropológicas (orientación en Arqueología), Facultad de Filosofía y Letras, Universidad de Buenos Aires.

Cartajena, I. \& L. Núñez, 2006. Purilacti: arte rupestre y tráfico de caravanas en la cuenca del salar de Atacama (norte de Chile). En Tramas en la piedra: Producción y usos del arte rupestre, D. Fiore \& M. M. Podestá, Eds., pp. 221-235. Buenos Aires: Sociedad Argentina de Antropología, AINA, WAC.

Copello, R., 1991 Ms. Loma Alta de Shiquimil. Instalaciones agrícolas y fuentes hídricas. Prospección del Lic. Sergio Caviglia. Informe para el Proyecto Arqueológico Yocavil.

Criado Boado, F., 1993. Visibilidad e interpretación del registro arqueológico. Trabajos de Prebistoria 50: 39-56, Madrid. 
De Hoyos, M. \& M. Lanza, 2000. Arte rupestre en San Antonio del Cajón, Provincia de Catamarca. Relaciones de la Sociedad Argentina de Antropología xxv: 119-144, Buenos Aires.

Fiadone, A. E., 2003. El diseño indígena argentino: Una aproximación estética a la iconografía precolombina. Buenos Aires: Editorial La Marca.

FIore, D., 1997 Ms. Analysis of Ampajango rock art, Santa María, Argentina: an approach to the structure of its designs and the technology of its production. MA Dissertation, Institute of Archaeology, University of London.

- 2007. The economic side of rock art: concepts on the production of visual images. Rock Art Research 24 (2): 149-160. Melbourne: AURA.

Frengueldi, J., 1936. Investigaciones geológicas en la zona salteña del valle de Santa María. En Obra del cincuentenario del Museo de La Plata, Vol. 2, pp. 185-200. La Plata: Universidad Nacional de La Plata, Instituto del Museo.

González, A. R., 1954. Las ruinas de Loma Rica y alrededores Publicaciones Técnicas de Natura 5 (1): 75-90, Buenos Aires

— 1977. Arte precolombino de la Argentina. Buenos Aires: Editorial Filmediciones Valero.

González A. R. \& J. A. PÉREz Gollán, 1966. El área andina meridional. En Actas del XXXVI Congreso de Americanistas I, pp. 33-48, Sevilla.

GONZÁLEZ, L. R., 2007. Tradición tecnológica y tradición expresiva en la metalurgia prehispánica del Noroeste Argentino. Boletín del Museo Chileno de Arte Precolombino 12 (2): 33-48.

GonzÁlez, L. R. \& M. N. TARragó, 2005. Vientos del sur. El valle de Yocavil (Noroeste Argentino) bajo la dominación inkaica. Estudios Atacameños 29: 67-95.

Gradín, C., 1978. Algunos aspectos del análisis de las manifestaciones rupestres. Revista del Museo Provincial, Tomo 1: 120-133, Neuquén.

Lanza, M. M., 2000. Análisis estilístico del arte rupestre del valle Calchaquí norte, Salta. En Arte en las rocas: Arte rupestre, menhires y piedras de colores en Argentina, M. M. Podestá \& M. de Hoyos, Eds., pp. 63-71. Buenos Aires: Sociedad Argentina de Antropología, AINA.

Ledesma, R. E., 2005. Contexto de producción de pinturas rupestres en El Divisadero (Cafayate, Salta, República Argentina). Andes 16: 305-323, Salta

2006/2007. Integración de sitios con arte rupestre y su territorio en la microrregión Cafayate (Provincia de Salta). Cuadernos del Instituto de Antropología y Pensamiento Latinoamericano 21: 115-131, Buenos Aires.

Ledesma, R. \& M. De Hoyos, 2001. El Divisadero: Cien años después... Arte rupestre en Cafayate, provincia de Salta. En Arte rupestre y región; arte rupestre, menbires y tacitas en el Sur de Bolivia, NO de Argentina y norte de Chile, Anuario del CEIC N ${ }^{\circ} 2$, A. Fernández Distel, Comp., pp. 151-164. San Salvador de Jujuy: Facultad de Humanidades y Ciencias Sociales, Universidad Nacional de Jujuy.

Ledesma, R. \& C. Subelza, 2009. Alcances y limitaciones para caracterizar las ocupaciones formativas en Cafayate (Salta). Andes 20: 75-109, Salta.

Liberani, I. \& R. Hernández, 1877. Excursión arqueológica en los valles de Santa María, Catamarca. Publicación 563, Instituto de Antropología, San Miguel de Tucumán.

Lo Celso, M. \& R. Ledesma, 2005. Sitios arqueológicos formativos en el Municipio de Cafayate (Salta). Avances de investigación. En I Jornadas de Antropología, pp. 267-282. Salta: Facultad de Humanidades, Universidad Nacional de Salta.

Lorandi, A. M., 1966. El arte rupestre del Noroeste Argentino. Área del norte de La Rioja y sur y centro de Catamarca. Dédalo 2 (4): 15-172, San Pablo.

McCormac, F. G.; A. G. Hogg, P. G. Blackwell, C. E. Buck, T. F. G. Higham \& P. J. Reimer, 2004. SHCal04 Southern Hemisphere calibration, 0-11.0 cal kyr BP. Radiocarbon 46 (3): 1087-1092, Arizona.
Nastri, J. H., 1997-1998. Patrones de asentamiento prehispánicos tardíos en el sudoeste del Valle de Santa María (Noroeste Argentino). Relaciones de la Sociedad Argentina de Antropología XXI-XXIII: 247-270, Buenos Aires.

2001. Interpretando al describir: la arqueología y las categorías del espacio aborigen en el valle de Santa María. Revista Española de Antropología Americana 31: 31-58, Madrid.

2006. El simbolismo en la cerámica de las sociedades tardías de los valles calchaquíes (siglos XI-XVI). Tesis doctoral, Facultad de Filosofía y Letras, Universidad de Buenos Aires.

Nastri J. H.; G. Pratolongo, A. Reynoso \& A. M. Vargas, 2009 Arqueología de la Sierra del Cajón: poblados, corrales y pinturas. En Problemáticas de la Arqueología Contemporánea, Tomo III, A. Austral \& M. Tamagnini, Comp., pp. 715-728. Río Cuarto: Editorial de la Universidad de Río Cuarto.

PANOFSKY, E., 1970 [1957]. El significado en las artes visuales. Buenos Aires: Ediciones Infinito.

Pelissero, N. \& H. Difrieri, 1981. Quilmes. Arqueología y etnobistoria de una ciudad prebistórica. Tucumán: Ediciones Gobierno de la Provincia de Tucumán.

Podestá, M. M., 1989. Punta del Pueblo: Expresiones del arte rupestre agroalfarero en la Puna Argentina. Boletín del SIARB 3: 38-47, La Paz.

Podestá, M. M.; D. Rolandi \& M. Sánchez Proaño, 2005. Arte rupestre de Argentina indigena. Noroeste. Buenos Aires Academia Nacional de la Historia y Union Académique International, GAC.

Quiroga, A., 1899. El simbolismo de la cruz y el falo en Calchaquí. Boletín del Instituto Geográfico Argentino, tomo x, cuadernos 7 a 12 , Buenos Aires

— 1900. Huayrapuca o La Madre del Viento. Boletín del Instituto Geográfico Argentino, tomo xx, cuadernos 7 a 12, Buenos Aires.

— 1931. Petrografías y pictografías de Calchaquí. Buenos Aires: Imprenta de la Universidad de Buenos Aires.

— 1992. Calchaquí. Buenos Aires: Editorial TEA

Raffino, R. A., 1991. Poblaciones indígenas en Argentina. Buenos Aires: Editorial TEA.

RENARD, S., 1988. Sitios arqueológicos con arte rupestre de la República Argentina. Registro/Documentación. Buenos Aires: FECIC.

— 1999. Textiles arqueológicos en el Noroeste de la Argentina: 100 siglos de actividad textil. Etnologiska Studier 43: 67-95, Etnografiska Museet i Göteborg.

Reynoso, A. \& G. Pratolongo, 2008. Jaguares de nuevo: consideraciones sobre la temática felínica en la iconografía cerámica del Período Tardío en Yocavil (Noroeste Argentino). Estudios Atacameños 35: 75-96.

Ruiz Huidobro, O. J., 1972. Descripción geológica de la hoja 11e, Santa María. Boletín 134. Buenos Aires: Ministerio de Industria y Minería, Subsecretaría de Minería, Servicio Nacional Minero Geológico.

Ruiz, M. \& D. Chorolque, 2007. Arte rupestre del Pukara de Rinconada: una larga bistoria visual. Jujuy: Universidad Nacional de Jujuy

Scattolin, M. C., 2000. Santa María durante el Primer Milenio AD. ¿Tierra baldía? Arstryck 1995-1998: 63-83, Etnografiska Museet i Göteborg.

— 2003. Recursos arquitectónicos y estilos cerámicos en los siglos Ix y x d.C. en el valle de Santa María. Taller "Local, regional, global: prehistoria, protohistoria e historia en los valles calchaquíes", Anales Nueva Época 6: 63-98, Göteborg.

— 2007. Santa María antes del año mil. Fechas y materiales para una historia cultural. En Sociedades precolombinas surandinas: Temporalidad, interacción y dinámica cultural del NOA en el ámbito de los Andes Centro-Sur, V. Williams, B. Ventura, A. Callegari \& H. Yacobaccio, Eds., pp. 203-219. Buenos Aires: Edición de los autores/Artes Gráficas Buschi S.A.

Scattolin, M. C.; M. F. Bugliani, L. I. Cortés, C. M. Calo, L. Pereyra Domingorena \& A. D. IzeTA, 2009. Pequeños mundos: hábitat, 
maneras de hacer y afinidades en aldeas del valle del Cajón, Catamarca. Relaciones de la Sociedad Argentina de Antropología XXXIV: 251-274, Buenos Aires.

SPANO, R. C., 2008. Indagaciones sobre las sociedades aldeanas del valle de Yocavil; análisis de la alfarería fina del sitio Soria 2 (Andalhuala, Provincia de Catamarca). Tesis de Licenciatura en Ciencias Antropológicas (orientación en Arqueología), Facultad de Filosofía y Letras, Universidad de Buenos Aires.

2010. Los pucos grabados post-cocción de una casa formativa (Sur de Yocavil). En Actas del XVII Congreso Nacional de Arqueología Argentina, tomo II, pp. 839-844, Mendoza.

TARragó, M. N., 1987. Sociedad y sistema de asentamiento en Yocavil. Cuadernos del Instituto Nacional de Antropología 12 179-196, Buenos Aires.

1995. Desarrollo Regional en Yocavil. Una estrategia de investigación. En Actas del XIII Congreso Nacional de Arqueología Chilena I, Simposios, pp. 225-235. Antofagasta de la Sierra: Universidad de Antofagasta de la Sierra / Instituto de Investigaciones Antropológicas.

2000. Chacras y pukara: Desarrollos sociales tardíos. En Nueva historia argentina: Los pueblos originarios y la Conquista, M. N. Tarragó, Ed., vol. 1, pp. 257-300. Buenos Aires: Sudamericana.
Tarragó, M. N.; S. Caviglia, M. M. Peralta Sanhuesa \& J. Sosa, 1988 Ms. Los grupos cerámicos del poblado de Loma Rica de Shiquimil, Catamarca, Argentina. Ponencia presentada al Ix Congreso Nacional de Arqueología Argentina, Buenos Aires.

Tarragó, M. N.; L. González \& J. NASTRI, 1997. Las interacciones prehispánicas a través del estilo: el caso de la iconografía santamariana. Estudios Atacameños 14: 223-242.

Tarragó, M. N. \& M. C. Scattolin, 1999. La problemática del Período Formativo en el valle de Santa María. En Actas del XII Congreso Nacional de Arqueología Argentina, C. Diez Marín, Ed., vol. I, pp. 142-153. La Plata: Universidad Nacional de La Plata.

Troncoso, A., 2005a. Genealogía de un entorno rupestre en Chile central: un espacio, tres paisajes, tres sentidos. Boletín del Museo Chileno de Arte Precolombino 10 (1): 35-53.

_ 2005b. Hacia una semiótica del arte rupestre de la cuenca superior del río Aconcagua, Chile central. Chungara 27 (1): 21-35.

Vargas, A. M. \& V. Palamarczuk, 1999 Ms. Morro la Mina I. Arte rupestre de la Provincia de Catamarca. Trabajo presentado en las III Jornadas de Estudiantes de Arqueología. Facultad de Filosofía y Letras, Universidad de Buenos Aires.

Williams, V., 2003. Nuevos datos sobre la prehistoria local en la Quebrada de Tolombón, Provincia de Salta, Argentina. Taller "Local, regional, global: prehistoria, protohistoria e historia en los valles calchaquíes", Anales Nueva Época 6: 163-209, Göteborg. 